\title{
Hydrodynamic analysis and simulation of a flow cell ammonia electrolyzer
}

\author{
Luis A. Diaz, and Gerardine G. Botte ${ }^{1 *}$ \\ Center for Electrochemical Engineering Research \\ Chemical and Biomolecular Engineering Department \\ Ohio University \\ 165 Stocker Center \\ Athens, OH 45701, USA \\ Phone: 740-593-9670
}

Fax: 740-593-0873

e-mail: botte@ohio.edu

A revised research paper submitted to

Electrochimica Acta

for consideration for publication

\footnotetext{
* Corresponding Author. Tel.: +1 740593 9670. Fax: +1 740593 0873. E-mail address: botte@ohio.edu (G.G. Botte).

1. ISE member
} 


\begin{abstract}
The hydrodynamic analysis and simulation of a non-ideal single pass flow cell alkaline ammonia electrolyzer was performed after the scale-up of a well-characterized deposited polycrystalline $\mathrm{Pt}$ on $\mathrm{Ni}$ anode. The hydrodynamic analysis was performed using the residence time distribution (RTD) test. The results of the hydrodynamic investigation provide additional insights for the kinetic analysis of the ammonia electrooxidation reaction on polycrystalline $\mathrm{Pt}$ electrocatalysts -which are typically obtained under controlled flow regime, e.g., rotating disk electrode- by including the flow non-uniformity present in the electrolyzer. Based on the RTD function, the ammonia electrolyzer performance was simulated as a non-steady stirred tank reactor (CSTR) and the unknown kinetic parameters were obtained by fitting the simulation results with an experimental current profile, obtaining an adequate prediction of the ammonia conversion. This simplified approach for the simulation of the ammonia electrolyzer could be implemented in process simulation packages and could be used for the design and scale-up of the process for hydrogen production and wastewater remediation.
\end{abstract}

Keywords: ammonia electrolysis; residence time distribution; ammonia conversion; electrolyzer simulation. 


\section{Introduction}

The oxidation of ammonia by means of electrochemical methods on Pt electrodes is an important reaction due to its application in different processes, such as the development of ammonia sensors [1], energy production through direct ammonia fuel cells [2], the removal of ammonia from domestic wastewater, and the treatment of industrial ammonia emissions [3]. Moreover, liquid ammonia is a promising alternative for hydrogen production $[4,5]$ due to its high volumetric hydrogen density $(45 \%$ higher volumetric hydrogen density than liquid hydrogen [6]) and high specific energy density in $\mathrm{kWh} \mathrm{L}^{-1}(50 \%$ higher energy density than liquid hydrogen [7-9]).

When ammonia electrooxidation in alkaline media (Equation (1)) is coupled with water reduction (Equation (2)), in a process known as ammonia electrolysis (Equation (3)) [10], it is theoretically possible to produce hydrogen with just five percent of the energy required from water electrolysis $[8,9]$. However, the lack of understanding of the reaction mechanism and kinetics has not allowed the full utilization and implementation of the technology in processes such as the electrochemical deammonification of wastewater [3].

$$
\begin{aligned}
& 2 \mathrm{NH}_{3(\mathrm{aq})}+6 \mathrm{OH}^{-} \rightarrow \mathrm{N}_{2}+6 \mathrm{H}_{2} \mathrm{O}+6 e^{-} \mathrm{E}^{\circ}=-0.77 \mathrm{~V} \text { vs. SHE } \\
& 6 \mathrm{H}_{2} \mathrm{O}+6 e^{-} \rightarrow 3 \mathrm{H}_{2}+6 \mathrm{OH}^{-} \mathrm{E}^{\circ}=-0.83 \mathrm{~V} \text { vs. SHE } \\
& 2 \mathrm{NH}_{3 \text { (aq) }} \rightarrow \mathrm{N}_{2}+3 \mathrm{H}_{2} \mathrm{E}_{\text {cell }}=0.06 \mathrm{~V}
\end{aligned}
$$

Diaz and Botte examined the intrinsic kinetics associated with the ammonia electrooxidation reaction in deposited polycrystalline Pt [11]. The authors developed a kinetic 
model, based on the reaction mechanism proposed by Gerischer and Mauerer [12], which accounts for two parallel reaction pathways. After the first dehydrogenation of ammonia, to absorbed amine $\left(-\mathrm{NH}_{2}\right)$, the formation of molecular nitrogen proceeds through the dimerization of amine to form hydrazine, which is subsequently oxidized to molecular nitrogen $\left(\mathrm{N}_{2}\right)$. At the potentials where ammonia electrooxidation takes place the oxidation of hydrazine is a fast process and can be considered as the irreversible step for the formation of molecular nitrogen [13]. On the other hand, the parallel reaction pathway follows the consecutive dehydrogenation of amine to atomic nitrogen, which ends with the deactivation of the active sites in the electrode. The model considers that ammonia is the only reactant adsorbed on the active sites, following an Eley-Rideal mechanism; therefore, the hydroxyl ions (Eq. 1) are not adsorbed and react from the solution.

The ammonia electrooxidation model developed by Diaz and Botte [11] was verified with the mathematical simulation of linear sweep voltammetry (LSV) experimental data in a welldefined hydrodynamic system, such as the rotating disk electrode (RDE). The authors obtained heterogeneous reaction kinetic constants through multiple parameters estimation with correlation coefficients of at least $\mathrm{R}^{2}=0.999$ against experimental data. It was concluded that the ammonia electrooxidation kinetics in polycrystalline $\mathrm{Pt}$ is a surface controlled process. Peak currents below the diffusion limiting current and the decay of the anodic current obtained during voltammetry experiments on polycrystalline Pt [14] (even at high rotational rates), are caused by the formation of deactivating adsorbates, such as adsorbed imine (NH-) and atomic nitrogen $(\mathrm{N})$. By means of the elucidation of the intrinsic kinetics obtained in the RDE electrodes it was expected to contribute to the design and scale up of the electrolyzer and deposited polycrystalline Pt electrode. 
However, in real world applications well define hydrodynamic conditions (as those obtained in the RDE system) are never obtained, therefore the simulation of the performance of the electrochemical reactor has to account for non-uniformity of the fluid flow, dead volumes, and inlet effects that affect the mass transfer of the species. Consequently, the identification of a well-known reactor model -such as plug flow reactor (PFR), continuous stirred tank reactor (CSTR), laminar reactor, etc.- is required for the establishment of mass balances [15]. In this paper, the hydrodynamic analysis of an ammonia single flow cell electrolyzer was performed in order to provide further insights of the ammonia electrooxidation reaction in a non-ideal reactor. The analysis extends an ammonia electrooxidation kinetic model, developed in previous research [11], to account for non-ideal flow conditions. The experimental approach included the scale-up of a well characterized Pt deposited on Ni substrate anode [11, 14], the analysis of the effect of the cathode in the ammonia electrooxidation using either $\mathrm{Pt}$ or $\mathrm{Ni}$ as cathodes, and the determination of the residence time distribution (RTD) function of the electrochemical reactor (which allows a characterization of the mixing behavior occurring within the electrolyzer and its effect on the ammonia electrolysis). The results obtained from the RTD analysis leaded to the simulation of the electrolyzer as a simple non-steady continuous stirred tank reactor (CSTR). The simulation results of the predicted conversion profile validated the use of the CSTR model to describe the performance of the ammonia electrolyzer for the tested hydrodynamic conditions.

\section{Experimental}

\subsection{Electrode preparation}

A $14.8 \mathrm{~cm}$ x $14.8 \mathrm{~cm}$ Ni gauze, Alfa Aesar 40 mesh woven, framed in a $0.25 \mathrm{~cm}$ thick border of Ni foil (Alfa Aesar $0.0127 \mathrm{~cm}$ thick, $99^{+} \% \mathrm{Ni}$ on metal basis), was used as electrode 
substrate. A Ni wire $2 \mathrm{~mm}$ diameter, annealed, $99.98 \%$ (metals basis), spot welded to the Ni frame was used as current connection. Electrode surface pretreatment was performed, before Pt electrodeposition, following the procedure presented by Diaz et al. [14]. The Ni foil frame was covered with a 3M 5480 polytetrafluoroethylene film tape to avoid deposition of $\mathrm{Pt}$ on the $\mathrm{Ni}$ frame.

Pt electrodeposition on the framed Ni gauze (FNG) electrode was performed in a $6 \mathrm{M}$ $\mathrm{NaOH}$ (Fisher Scientific ${ }$, 99.5\%) plus $2.4 \mathrm{~g} \mathrm{~L}^{-1} \mathrm{H}_{2} \mathrm{Cl}_{6} \mathrm{Pt}^{*} 6 \mathrm{H}_{2} \mathrm{O}$ (Alfa Aesar ${ }^{\circledR}, 99.9 \%$ ) solution using a Solartron $1470 \mathrm{E}$ potentiostat. Electrodeposition conditions used (-0.6 V vs. $\mathrm{Hg} / \mathrm{HgO}, 50$ ${ }^{\circ} \mathrm{C}$, and $80 \mathrm{~min}$ for applied potential, deposition temperature, and deposition time, respectively) were previously defined by Diaz et al. [14]. A customized three-electrode cell was built (dimensions: $15.5 \mathrm{~cm}$ length, $19.5 \mathrm{~cm}$ height, and $3.2 \mathrm{~cm}$ width) with chlorinated polyvinyl chloride (CPVC) sheets. Detail dimensions are provided in Figure 1. The auxiliary electrodes were two $15.2 \mathrm{~cm}$ x $19 \mathrm{~cm}$ Pt of $0.01 \mathrm{~cm}$ thickness and $99.999 \%$ purity (ESPI metals) foils connected in parallel and placed $1.5 \mathrm{~cm}$ apart from each face of the framed Ni gauze electrode. A $\mathrm{Hg} / \mathrm{HgO}$ electrode (Koslow Scientific, Inc.) immersed in a Luggin capillary filled with $6 \mathrm{M}$ $\mathrm{NaOH}$ was used as reference electrode. The electrodeposition solution temperature was controlled with an Isotemp 3013HD heated recirculating bath. Ultrapure water (>18 $\mathrm{M} \Omega$ ) was used to prepare all the solutions used in this work. Finally, Pt loading was measured by mean of weight change after electrodeposition.

\subsection{Electrochemical measurements}

An open three electrode cell configuration, formerly described, was used to test the electrochemical activity of the electrode in $0.1 \mathrm{M} \mathrm{KOH}$ (Fisher Scientific $®$, >85\%) solution, 
where the electrochemical active surface area of the electrode was measured by means of $\mathrm{CO}$ adsorption and striping as described by Diaz et al. [14]. A $\mathrm{Hg} / \mathrm{HgO}$ electrode in a Luggin capillary and two Pt $(15.2 \mathrm{~cm} \times 19 \mathrm{~cm})$ foils were used as reference and auxiliary electrodes, respectively. Cyclic voltammetry $(\mathrm{CV})$ and potential steps experiments were performed, with a Solartron 1470 E potentiostat, to examine the catalytic activity towards ammonia electrooxidation in $0.1 \mathrm{M} \mathrm{KOH}+0.01 \mathrm{M} \mathrm{NH}_{4} \mathrm{Cl}($ Alfa Aesar® $99.5 \%)$ solution. Either two Pt $(15.2 \mathrm{~cm}$ x $19 \mathrm{~cm})$ foils or two $14.8 \mathrm{~cm}$ x $14.8 \mathrm{~cm}$ expanded Ni plate, connected in parallel and placed at each face of the FNG electrode, were tested as auxiliary electrodes to examine the effect of the cathode in the cell voltage. The voltage difference among working and auxiliary electrodes (cell voltage) was also measured using the Solartron 1470E potentiostat.

\subsection{Residence time distribution (RTD)}

The RTD analysis was performed in a flow cell parallel electrode assembly detailed in the insert of Figure 1 [16]. Electrodes were held in position using small Teflon wedges at the corners of the electrode. A single step perturbation was applied using the experimental set up presented in Figure 1. $0.1 \mathrm{M} \mathrm{KOH}+0.01 \mathrm{M} \mathrm{NH}_{4} \mathrm{Cl}$ solution was fed into the electrolyzer at a flow rate of $1.8 \mathrm{~mL} \mathrm{~min}^{-1}$. Once the flow rate was stabilized, a fixed potential, defined from the preliminary electrochemical analysis, was applied. After one hour of applied potential, the three way valves on Figure 1 were open to a solution of $200 \mu \mathrm{L} \mathrm{L}^{-1}$ of Yellow 5 dye (Tracer) in $0.1 \mathrm{M}$ $\mathrm{KOH}+0.01 \mathrm{M} \mathrm{NH}_{4} \mathrm{Cl}$. The concentration of Yellow 5 was measured every $30 \mathrm{~s}$ at the exit of the reactor using a Hewlett Packard $80 \mu \mathrm{L}$ quartz QS 1.000 compact fluid cell in an Agilent 8453 spectrophotometer at $400 \mathrm{~nm}$. Yellow 5 dye was found to have no significant effect in the ammonia electrooxidation current-potential profile as it is presented in Figure 2. 


\section{Results and Discussion}

\subsection{Electrode preparation and characterization}

The amount of Pt deposited on the FNG electrode, measured by weight change, was $0.048 \mathrm{~g} \pm 0.001 \mathrm{~g}$ of Pt. This loading was obtained with an experimental charge of $249 \mathrm{C}$, which accounts for a Faraday efficiency of $38 \%$ for the electrodeposition process. The FNG electrode geometric area (EGA) was calculated as $251.2 \mathrm{~cm}^{2}$ (following the procedure described by Zhang et al. [17]), whereas the electrochemical active surface area (EASA) measured by means of CO adsorption and stripping [13] was $5600 \mathrm{~cm}^{2} \pm 40 \mathrm{~cm}^{2}$. Figure 2 shows the sustained periodic state CV (reached at the $5^{\text {th }}$ cycle) of the working electrode (Pt deposited on FNG) using the Pt foils as auxiliary electrodes at a scan rate of $10 \mathrm{mV} \mathrm{s}^{-1}$. The CVs were performed before and after the addition of $150 \mu \mathrm{L}$ of Yellow 5 dye in $750 \mathrm{~mL}$ of $0.1 \mathrm{M} \mathrm{KOH}$ and $0.1 \mathrm{M} \mathrm{KOH}+0.01 \mathrm{M}$ $\mathrm{NH}_{4} \mathrm{Cl}$ solutions.

The hydrogen under potential deposition region $\mathrm{H}_{\mathrm{UPD}}$, characteristic of polycrystalline $\mathrm{Pt}$ [14], can be observed in the ammonia free solutions CVs presented on Figure 2 at the potential region from -0.75 to $-0.4 \mathrm{~V}$ vs. $\mathrm{Hg} / \mathrm{HgO}$. In the presence of ammonia a current peak ca. $-0.1 \mathrm{~V}$ vs. $\mathrm{Hg} / \mathrm{HgO}$, attributed to the ammonia electrooxidation, is observed. It is also observed that the presence of the Yellow 5 dye does not significantly affect the current potential profiles of the ammonia electrooxidation, therefore Yellow 5 dye can be used as tracer for the RTD tests while a potential is applied. It is fundamental for the RTD studies to use an inert tracer that can be applied in-situ, while the ammonia electrolysis proceeds, because the evolution of gases $\left(\mathrm{N}_{2}\right.$ and $\mathrm{H}_{2}$ ) during ammonia electrooxidation reaction affects the flow profiles inside the electrolyzer. Misleading results could be obtained from ex-situ RTD analysis. 
Potential staircase experiments were performed in $0.1 \mathrm{M} \mathrm{KOH}+0.01 \mathrm{M} \mathrm{NH}_{4} \mathrm{Cl}$ solution, from $-0.35 \mathrm{~V}$ vs. $\mathrm{Hg} / \mathrm{HgO}$ to $-0.025 \mathrm{~V}$ vs. $\mathrm{Hg} / \mathrm{HgO}$ with a potential increment of $0.025 \mathrm{~V}$ and 10 min step size. Figure 3 shows the polarization curves obtained from the average current featured during the last five minutes of each potential step. The decrease in the measured current density after $-0.2 \mathrm{~V}$ vs. $\mathrm{Hg} / \mathrm{HgO}$ is attributed to catalyst deactivation due to surface blockage by intermediate adsorbates in agreement with the reaction mechanism proposed by Diaz and Botte [11]. Figure 3a shows that the same performance can be obtained using either Pt foil or expanded $\mathrm{Ni}$ as auxiliary electrodes at the same potential of the working electrode versus the reference electrode. However, by measuring the voltage difference among working and auxiliary electrodes, it was possible to determine that higher cell voltages are required when expanded $\mathrm{Ni}$ is used as cathode instead of Pt foil (Figure 3b). This difference can be explained from the higher over potentials required for the hydrogen evolution on $\mathrm{Ni}$ than on Pt [18]. The similar currentpotential profiles obtained with either $\mathrm{Pt}$ or $\mathrm{Ni}$ as auxiliary electrodes (Figure 3a), identify the electrooxidation of ammonia on the Pt deposited on FNG electrode as the controlling reaction in the ammonia electrolysis process. Therefore, the use of non noble metals such as $\mathrm{Ni}$ as the cathode (although increase the voltage required for the process) could reduce the capital costs of the ammonia electrolyzer while still operating at voltages much lower than water electrolysis. This feature is important for possible integration with a fuel cell, where the energy required to generate $\mathrm{H}_{2}$ is lower than the potential energy of the fuel cell, making the process self sustainable. In addition, the use of non noble metals for the cathode can play a significant role on the application of the process in wastewater treatment plants where the volumes of flow are large and may require large electrolyzers. Hereinafter, expanded $\mathrm{Ni}$ was used as auxiliary electrode for the long-term potential step experiments, and in the flow cell electrolyzer. 
Based on the current densities displayed in Figures 2 and 3 the best electrode performance should be expected between -0.2 to $-0.1 \mathrm{~V}$ vs. $\mathrm{Hg} / \mathrm{HgO}$. Hence, constant potential tests were performed in $0.1 \mathrm{M} \mathrm{KOH}+0.01 \mathrm{M} \mathrm{NH}_{4} \mathrm{Cl}$ solution, sweeping the potential at $10 \mathrm{mV}$ $\mathrm{s}^{-1}$ from $-0.95 \mathrm{~V}$ vs. $\mathrm{Hg} / \mathrm{HgO}$ to $-0.2,-0.15$, and $-0.1 \mathrm{~V}$ vs. $\mathrm{Hg} / \mathrm{HgO}$, respectively, and holding each potential for one hour. Then, a reversed sweep scan at $10 \mathrm{mV} \mathrm{s}^{-1}$ from the applied potential (either $-0.2,-0.15$, or $-0.1 \mathrm{~V}$ vs. $\mathrm{Hg} / \mathrm{HgO}$ ) back to $-0.95 \mathrm{~V}$ vs. $\mathrm{Hg} / \mathrm{HgO}$ was performed to evaluate the effect of the applied potential in the amount of adsorbed species. This was achieved measuring the charge required to reduce the adsorbed intermediates back to ammonia $\mathrm{NH}_{3}$.

Figure $4 \mathrm{a}, \mathrm{b}$, and c show the anodic scans, the current profile for the constant potential step, and the cathodic scans, respectively. The measured cell voltage profile is shown on Figure 4d. Higher current densities are reached at higher upper limit potentials as shown in the potential scans in Figure 4a. However, Figure 4b shows that the higher the applied potential the faster the drop in the current density, where the initial current density of the constant potential step is equal to the final current density observed in the anodic scan presented in Figure 4a. These phenomena can be explained based on the reductive potential scans presented in Figure $4 \mathrm{c}$. The charge of the cathodic peak ca. $-0.5 \mathrm{~V}$ vs. $\mathrm{Hg} / \mathrm{HgO}$, which is associated to the reduction of adsorbed intermediates back to $\mathrm{NH}_{3}$ [19], is $0.64,0.70$, and $0.77 \mathrm{C}$ after the step potentials of $-0.2,-0.15$, and $-0.1 \mathrm{~V}$ vs. $\mathrm{Hg} / \mathrm{HgO}$, respectively. Assuming atomic nitrogen $\left(\mathrm{N}_{\mathrm{ads}}\right)$ as the main adsorbate [19], the fractional coverage of adsorbed intermediates would be $0.18,0.20$, and 0.22 for each upper potential limit. These results reveal a higher coverage of adsorbed intermediates, possibly leading towards the electrode deactivation, at higher applied potentials as discussed in the reaction mechanism proposed by Diaz and Botte [11]. The applied potential of $-0.2 \mathrm{~V}$ vs. $\mathrm{Hg} / \mathrm{HgO}$ shows a higher and more stable current density profile, which agrees with the more 
stable measured cell voltage profile presented in Figure $4 \mathrm{~d}$ ca. $0.86 \mathrm{~V}$. An applied potential of $0.2 \mathrm{~V}$ vs. $\mathrm{Hg} / \mathrm{HgO}$ was then used for the RTD analysis.

\subsection{RTD results}

Rigorous approaches, such as computational fluid dynamics (CFD), can be used to describe the hydrodynamic behavior of flow systems. However, the analysis of the residence time distribution in the electrolyzer allows the development of simple reactor models and can provide sufficient information for the electrolyzer design. Therefore, the cumulative RTD function $\mathrm{F}(\mathrm{t})$ of a flow cell ammonia electrolyzer (Figure 5) was measured using the electrolyzer set-up described in Figure 1, for a flow rate of $1.8 \mathrm{~mL} \mathrm{~min}^{-1}$. A PFR-CSTR in series model (Equation (4)) was found to describe adequately the experimental cumulative RTD function $\mathrm{F}(\mathrm{t})$ of the electrolyzer with a correlation coefficient $\mathrm{R}^{2}=0.995$ as presented in Figure 5. A comparison of the PFR-CSTR model with ideal models, such as PFR, CSTR, and laminar flow reactor can also be observed on Figure 5 . The residence time for the PFR $\dot{t}_{P}=4762.9 \mathrm{~s}$, and a mean residence time for the CSTR $\dot{t}_{s}=31685.3 \mathrm{~s}$ were calculated using the solver function in Microsoft Excel ${ }^{\circledR}$ minimizing the sum of square residuals.

$$
F(t)= \begin{cases}0 & ; t<\dot{t}_{p} \\ 1-e^{\frac{t-\dot{t}_{p}}{\dot{t}_{s}}} & ; \mathrm{t} \geq \dot{t}_{p}\end{cases}
$$

The PFR section of the PFR-CSTR model represents the balance of the electrolyzer system in which no reaction is taking place such as the gas splitter and tubing (fluid lines) in Figure 1. The total PFR volume calculated from the RTD was $\mathrm{V}_{\mathrm{PFR}}=140.9 \mathrm{~mL}$. On the other 
hand, the volume calculated for the CSTR, $\mathrm{V}_{\mathrm{CSTR}}=950.6 \mathrm{~mL}$, could represent the parallel plate flow electrolyzer. Although it could have been expected from the RTD, based on the low flow rate tested, the identification of some segregated flow features, such as preferential flow or dead zones in the electrolyzer, the CSTR behavior is possibly caused by the effect of the gases evolving from the electrode and/or the rapid expansion of the fluid leaving entering the electrolyzer (Figure 1). Therefore, in order to verify whether the electrolyzer can be represented by a CSTR model, a simulation of the ammonia electrolysis at constant potential was performed computing the ammonia electrolyzer as a CSTR with the mean residence time obtained from the PFR-CSTR model. The simulation results were then compared with experimental data (current density and ammonia conversion).

\subsection{Electrolyzer simulation Differences in the first points cannot be avoided completely} because the simulation does not account for the non-faradic current or charge that is produced by the potential step.

The kinetic expression required to simulate the behavior of the ammonia electrolyzer as a CSTR under controlled constant potential was developed by Diaz and Botte [11] (from the reaction mechanism described in Equations (5) to (9)), where Equation (6) was identified as the rate determining step for the formation of $\mathrm{N}_{2}$. The current density expression for the ammonia electrooxidation process is given by Equation (10) [11].

$$
\begin{aligned}
& \text { Reaction } 1 \mathrm{Pt}+\mathrm{NH}_{3}+\mathrm{OH}^{-} \underset{k_{1 b}}{\stackrel{k_{1 f}}{\rightleftharpoons}} \mathrm{PtNH}_{2}+\mathrm{H}_{2} \mathrm{O}+e^{-} \\
& \text {Reaction } 22 \mathrm{PtNH}_{2} \underset{\mathrm{k}_{2 b}}{\stackrel{k_{2 f}}{\rightleftharpoons}} \mathrm{PtN}_{2} \mathrm{H}_{4}+\mathrm{Pt}
\end{aligned}
$$




$$
j=\left(\frac{E A S A}{E G A}\right) F\left(\begin{array}{l}
n_{1}\left(k_{1 f} C_{N H_{3}} C_{O H^{-}} \theta \cdot \mathrm{e}^{\frac{\alpha_{1} \cdot F \cdot\left(V d-\phi-U j r e f_{1}\right)}{R \cdot T}}-k_{1 b} \theta_{N H_{2}} \cdot \mathrm{e}^{-\frac{\left(1-\alpha_{1}\right) \cdot F \cdot\left(V d-\phi-U j r e f_{1}\right)}{R \cdot T}}\right) \\
+n_{2} k_{2 f} \theta_{N H_{2}}^{2}+n_{4}\left(k_{4 f} \theta_{N H_{2}} C_{O H^{-}} \mathrm{e}^{\frac{\alpha_{4} \cdot F \cdot\left(V d-\phi-U j r f_{4}\right)}{R \cdot T}}-k_{4 b} \theta_{N H} \cdot \mathrm{e}^{-\frac{\left(1-\alpha_{4}\right) \cdot F \cdot\left(V d-\phi-U j r e f_{4}\right)}{R \cdot T}}\right) \\
+n_{5}\left(k_{5 f} \theta_{N H} C_{O H^{-}} \cdot \mathrm{e}^{\frac{\alpha_{5} \cdot F \cdot\left(V d-\phi-U j r e f_{5}\right)}{R \cdot T}}-k_{5 b} \theta_{N} \cdot \mathrm{e}^{-\frac{\left(1-\alpha_{5}\right) \cdot F \cdot\left(V d-\phi-U j r e f_{5}\right)}{R \cdot T}}\right)
\end{array}\right)
$$

where $V d$ is the applied potential vs. $\mathrm{Hg} / \mathrm{HgO}$ and $\phi$ is the electrolyte potential.

The other parameters and variables used in Equation (10) are described in Table 1. Figure 5 shows that the PFR-CSTR model is the hydrodynamic model that better describes the RTD function of the electrolyzer, even better than the laminar flow reactor (which could be the model that better represent the conditions obtained in the RDE experiments reported in previous work $[11,14])$. The laminar flow model is a model of a segregated flow in which the flow moves in layers inside the electrolyzer without mixing. However, the CSTR model assumes a complete mixing of the volume inside the reactor. Because the CSTR model was implemented (homogeneous concentration throughout the reactor), and the current featured by the ammonia electrooxidation reaction is much lower than the mass transfer limiting current [14], the concentration over potential was neglected [20,21]. 
The mass balance in the CSTR model was developed taking ammonia as the key component as shown in Equation (11) where $-r_{N H_{3}}\left(\mathrm{~mol} \mathrm{~cm} \mathrm{cs}^{-2}\right)$, is the ammonia consumption rate and $\mathrm{Q}\left(\mathrm{cm}^{3} \mathrm{~s}^{-1}\right)$ is the volumetric flow rate.

$$
C_{N_{3}(\text { in })}-C_{N_{3}(\text { out })}-r_{N H_{3}}\left(\frac{E A S A}{Q}\right)=\dot{t}_{s} \frac{d C_{N H_{3}(\text { out })}}{d t}
$$

Based on the first term inside the big parenthesis in Equation (10), the ammonia consumption rate, which is first order with respect to ammonia, could be assumed as an overall first order reaction if the concentration of $\mathrm{OH}^{-}$and the concentration of unoccupied active sites ( $\theta$ ) remain constant. This assumption is reasonable for $\mathrm{OH}^{-}$concentration because the amount of $\mathrm{OH}^{-}$that is consumed in the anode, ammonia electrooxidation (Equation (1)), is generated in the cathode, water reduction reaction (Equation (2)). However, the concentration of available active sites changes with time due to the formation of adsorbed intermediates and the deactivation of the catalyst (as shown in Figure 4). Therefore, the transient mass balance of the adsorbed intermediates $\left(\theta_{\mathrm{NH}_{2}}, \theta_{\mathrm{NH}}, \theta_{N}\right)$ and $\boldsymbol{\theta}$ presented in Equations (12) to (15) [11] were simultaneously solved along with the mass balance of ammonia in Equation (11), to complete the number of equations required by the number of variables $(M)$ in Equation (10) $(M=5)$,

$$
\begin{aligned}
& k_{1 f} C_{N H_{3}} C_{O H^{-}} \theta \cdot \mathrm{e}^{\frac{\alpha_{1} \cdot F \cdot \eta_{1}}{R \cdot T}}-k_{1 b} \theta_{N H_{2}} \cdot \mathrm{e}^{-\frac{\left(1-\alpha_{1}\right) \cdot F \cdot \eta_{1}}{R \cdot T}}-k_{4 f} \theta_{N H_{2}} \cdot C_{O H^{-}} \cdot \mathrm{e}^{\frac{\alpha_{4} \cdot F \cdot \eta_{4}}{R \cdot T}} \\
& +k_{4 b} \theta_{N H} \cdot \mathrm{e}^{-\frac{\left(1-\alpha_{4}\right) \cdot F \cdot \eta_{4}}{R \cdot T}}-k_{2 f} \theta_{N H_{2}}^{2}=\frac{\Gamma \cdot d \theta_{N H_{2}}}{d t}
\end{aligned}
$$




$$
\begin{aligned}
& k_{4 f} \theta_{N H_{2}} C_{O H^{-}} \cdot \mathrm{e}^{\frac{\alpha_{4} \cdot F \cdot \eta_{4}}{R \cdot T}}-k_{4 b} \theta_{N H} \cdot \mathrm{e}^{-\frac{\left(1-\alpha_{4}\right) \cdot F \cdot \eta_{4}}{R \cdot T}}-k_{5 f} \theta_{N H} C_{O H^{-}} \cdot \mathrm{e}^{\frac{\alpha_{5} \cdot F \cdot \eta_{5}}{R \cdot T}} \\
& +k_{5 b} \theta_{N} \cdot \mathrm{e}^{-\frac{\left(1-\alpha_{5}\right) \cdot F \cdot \eta_{5}}{R \cdot T}}=\frac{\Gamma \cdot d \theta_{N H}}{d t} \\
& k_{5 f} \theta_{N H} C_{O H^{-}} \cdot \mathrm{e}^{\frac{\alpha_{5} \cdot F \cdot \eta_{5}}{R \cdot T}}-k_{5 b} \theta_{N} \cdot \mathrm{e}^{-\frac{\left(1-\alpha_{5}\right) \cdot F \cdot \eta_{5}}{R \cdot T}}=\frac{\Gamma \cdot d \theta_{N}}{d t} \\
& 1=\theta+\theta_{N H_{2}}+\theta_{N H}+\theta_{N}
\end{aligned}
$$

where $\Gamma$ is the surface concentration of active sites calculated from the adsorption charge density of a monolayer of hydrogen on polycrystalline $\mathrm{Pt}\left(210 \mu \mathrm{C} \mathrm{cm}^{-2}\right)$ [22].

The values of the kinetic parameters such as heterogeneous reaction constants $k_{i f}$ and formal potentials Ujref $_{i} \mathrm{vs} . \mathrm{Hg} / \mathrm{HgO}$, where $i$ is the number of the reaction in Equations (5) to (9), were obtained from the mathematical model of ammonia-electrooxidation in a rotating disk electrode (RDE) system during linear sweep voltammetry (LSV) perturbation and reported elsewhere [11]. As the value of the reversed heterogeneous reaction constants $k_{i b}$ were found to be no-significant for the RDE-LSV model, the reversed reaction terms in Equations (10) to (15) were initially excluded from the simulation equations. The linearly independent first order ordinary differential Equations (Equations (11), and (12) to (14)) were solved using the explicit Euler method [23] implemented in Microsoft Excel ${ }^{\circledR}$, with the initial values and time step size $\Delta t$ presented in Table 1. The value of $\Delta t$ was chosen based on the time interval in which the experimental data was collected by the Solartron 1470 E potentiostat. The results of the solution reached for the simulation are stable and independent of $\Delta t$.

The simulation results, which were obtained neglecting the effect of the reversed reaction, show a rapid decrease of the current profile regardless of the applied potential. It was 
then concluded that although the effect of the reverse reactions in Equations (5) to (9) may be insignificant when the potential is swept in a positive (oxidative) direction, the reactions in equilibrium become important when the applied potential is kept constant. Therefore, the value of the missing parameters in Equation (10) $\left(k_{1 b}, k_{4 b}, k_{5 b}\right)$ were calculated fitting the simulated current profile with the experimental current profile obtained at $-0.2 \mathrm{~V}$ vs. $\mathrm{Hg} / \mathrm{HgO}$.

The best estimated parameter values that provided a correlation coefficient $R^{2}=0.98$ are listed in Table 1. Figure 6 shows the fitted simulation and experimental current profiles of the single flow cell electrolyzer with the Pt deposited Ni framed electrode as working electrode, expanded $\mathrm{Ni}$ electrode as auxiliary electrode, an applied potential of $-0.2 \mathrm{~V}$ vs. $\mathrm{Hg} / \mathrm{HgO}$, and a feed of $1.8 \mathrm{~mL} \mathrm{~min}^{-1}$ of a $0.1 \mathrm{MKOH}+0.01 \mathrm{M} \mathrm{NH}_{4} \mathrm{Cl}$ solution. The noise observed in the experimentally recorded current density can be attributed to the effects of the bubbles growing and leaving the surface of the electrode as the reaction proceeds. The insert on Figure 6 shows the catalyst coverage profile predicted by the simulation.

In addition to the current profiles, the simulation provides the ammonia conversion profile in the ammonia electrolyzer, which is compared against experimental measurements in Figure 7. The measurement of the experimental fractional conversion was performed as reported by Diaz and Botte [3].

The results presented in Figure 6 and Figure 7 show adequate agreement among the experimental performance of the ammonia electrolyzer and the electrolyzer simulation as a CSTR reactor. The experimental and simulated ammonia conversion profile are compared in Figure 7 providing a standard estimation error $\mathrm{S}_{\mathrm{est}}=10.1 \%$. The maximum error regarding the predicted conversion of the simulation was observed with the last experimental fractional conversion measured ca. $26 \%$. Higher experimental conversions compared with the predicted 
value could be attributed to the $\mathrm{NH}_{3}$ stripping caused by the evolution of gases $\left(\mathrm{N}_{2}\right.$ and $\left.\mathrm{H}_{2}\right)$ in the electrolyzer.

The simulation of the electrolyzer was validated with a different data set obtained at the same conditions of flow and applied potential, but different feed compositions. Figure 8 shows a comparison of the experimental and simulated profiles obtained for the ammonia electrolyzer at $0.2 \mathrm{~V}$ vs. $\mathrm{Hg} / \mathrm{HgO}, 1.8 \mathrm{~mL} \mathrm{~min}^{-1}$ and a feed composition of $0.07 \mathrm{M} \mathrm{NH}_{4} \mathrm{Cl}+0.15 \mathrm{M} \mathrm{KOH}$ obtaining a correlation coefficient $\mathrm{R}^{2}=0.89$. Good agreement among experimental and simulated values were obtained after $6000 \mathrm{~s}$. Both simulated and experimental profiles show a reduction of the current density produced by the increase of the $\mathrm{KOH}$ concentration in the feed. This can be explained comparing the catalyst surface coverage profiles on the inserts of Figures 6 and 8 where higher $\mathrm{OH}^{-}$concentrations enhance the catalyst poisoning (Equation 8 and 9). Differences among the experimental and predicted current profiles during the initial points cannot be avoided completely because: first the simulation assumes that the active sites are initially vacant, which may not be happening during the experiment, and second the kinetic model does not account for the non-faradic current that is produced by the potential step. Moreover, Some parameters, such as $k_{4 f}, k_{5 f}$, which may require refinement as a low sensitivity was observed when fitted to predict the LSV of the ammonia electrooxidation [11]. The assumptions imbedded in the hydrodynamic model could also affect the final outcome of the simulation mostly when lower currents will reduce the amount of gases evolved in the electrode affecting the mixing inside the electrolyzer. The use of hydrodynamic models with a bigger number of parameters (i.e. axial dispersion or reactors in series) could add more accuracy to the simulations but it will require more complex calculations. 


\section{Conclusions}

The hydrodynamic analysis performed to a single flow cell ammonia electrolyzer established the presence of an extensive degree of mixing within the electrolyzer, which supports that the residence time distribution function of the electrolyzer system can be represented using the residence time distribution function of a PFR-CSTR system. Additionally, the results obtained by means of experimental electrochemical analysis explain the effects of the adsorbed intermediates in the ammonia electrooxidation performance, in which the applied potential appears as the most important control variable to reduce the fast poisoning and contamination of the catalyst. The CSTR model was found to provide a satisfactory representation of the ammonia electrolyzer at the tested conditions. A successful simulation of the ammonia electrolyzer as a CSTR was possible after fitting the unknown kinetic parameters $\left(k_{1 b}, k_{4 b}, k_{5 b}\right)$ with the current profile obtained at $-0.2 \mathrm{~V}$ vs. $\mathrm{Hg} / \mathrm{HgO}$, which allowed an adequate representation of the conversion profile of the electrolyzer. However, a more accurate simulation of the ammonia electrolyzer will require the use of a hydrodynamic model with more than one parameter and multidimensional calculations. 


\section{Acknowledgements}

The authors would like to thank the financial support of the Center for Electrochemical Engineering Research (CEER) at Ohio University and the Department of Defense through the U.S. Army Construction Engineering Research Laboratory (W9132T-09-1-0001). The content of the information does not reflect the position or the policy of the U.S. government. 


\section{References}

[1] B.A. López de Mishima, D. Lescano, T. Molina Holgado, H.T. Mishima, Electrochemical oxidation of ammonia in alkaline solutions: its application to an amperometric sensor, Electrochim. Acta 43 (1998) 395-404.

[2] L. Zhang, Y. Cong, W. Yang, L. Lin, A Direct Ammonia Tubular Solid Oxide Fuel Cell, Chin. J. Catal. 28 (2007) 749-751.

[3] L.A. Diaz, G.G. Botte, Electrochemical deammonification of synthetic swine wastewater, Ind. Eng. Chem. Res. 51 (2012) 12167-12172.

[4] B.K. Boggs, G.G. Botte, On-board hydrogen storage and production: An application of ammonia electrolysis, J. Power Sources 192 (2009) 573-581.

[5] R. Palaniappan, D.C. Ingram, G.G. Botte, Hydrogen Evolution Reaction Kinetics on Electrodeposited Pt-M (M = Ir, Ru, Rh, and Ni) Cathodes for Ammonia Electrolysis, J. Electrochem. Soc. 161 (2014) E1-E11.

[6] M. Muthuvel, G.G. Botte, Trends in ammonia electrolysis, in: R.E. White, C.G. Vayenas, M.E. Gamboa-Aldeco (Eds.), Modern Aspects of Electrochemistry, Springer, 2009, pp. 207-245.

[7] M. Cooper, G.G. Botte, Hydrogen production from the electrooxidation of ammonia catalyzed by platinum and rhodium on raney nickel substrate, J. Electrochem. Soc. 153 (2006) A1894-A1901. 
[8] F. Vitse, M. Cooper, G.G. Botte, On the use of ammonia electrolysis for hydrogen production, J. Power Sources 142 (2005) 18-26.

[9] F. Vitse, M. Cooper, G.G. Botte, Erratum to "On the use of ammonia electrolysis for hydrogen production" [J. Power Sources 142 (2005) 18-26], J. Power Sources 152 (2005) 311312.

[10] G. G. Botte, Electro-catalysts for the oxidation of ammonia in alkaline media, U.S. Patent No. 7,803,264 (2010).

[11] L.A. Diaz, G.G. Botte, Mathematical modeling of ammonia electrooxidation kinetics in a polycrystalline Pt rotating disk electrode, Electrochim. Acta (2014), doi:10.1016/j.electacta.2014.12.162.

[12] H. Gerischer, A. Mauerer, Untersuchungen Zur anodischen Oxidation von Ammoniak an Platin-Elektroden, J. Electroanal. Chem. Interfacial Electrochem. 25 (1970) 421-433.

[13] V. Rosca, M.T.M. Koper, Electrocatalytic oxidation of ammonia on $\operatorname{Pt}(111)$ and $\operatorname{Pt}(100)$ surfaces, Phys. Chem. Chem. Phys. 8 (2006) 2513-2524.

[14] L.A. Diaz, A. Valenzuela-Muñiz, M. Muthuvel, G.G. Botte, Analysis of ammonia electrooxidation kinetics using a rotating disk electrode, Electrochim. Acta 89 (2013) 413-421.

[15] J. González-García, V. Montiel, A. Aldaz, J.A. Conesa, J.R. Pérez, G. Codina, Hydrodynamic behavior of a filter-press electrochemical reactor with carbon felt as a threedimensional electrode, Ind. Eng. Chem. Res. 37 (1998) 4501-4511. 
[16] G. G. Botte, C. A. Feickert, Electro Decomposition of Ammonia into Hydrogen for Fuel

$\begin{array}{lll}\text { Cell } & \text { Use, } & \text { ADA559187 }\end{array}$

(2012),

http://oai.dtic.mil/oai/oai?verb=getRecord\&metadataPrefix=html\&identifier=ADA559187.

[17] Y. Zhang, M.D. Merrill, B.E. Logan, The use and optimization of stainless steel mesh cathodes in microbial electrolysis cells, Int. J. Hydrogen Energy 35 (2010) 12020-12028.

[18] W. Sheng, M. Myint, J.G. Chen, Y. Yan, Correlating the hydrogen evolution reaction activity in alkaline electrolytes with the hydrogen binding energy on monometallic surfaces, Energy Environ. Sci. 6 (2013) 1509-1512.

[19] J.F.E. Gootzen, A.H. Wonders, W. Visscher, R.A. van Santen, J.A.R. van Veen, A DEMS and cyclic voltammetry study of $\mathrm{NH}_{3}$ oxidation on platinized platinum, Electrochim. Acta 43 (1998) 1851-1861.

[20] J.S. Newman, K.E. Thomas-Alyea, Electrochemical Systems, 3rd ed., J. Wiley, Hoboken, N.J., 2004.

[21] A.J. Bard, L.R. Faulkner, Electrochemical Methods: Fundamentals and Applications, 2nd ed., Wiley, New York, 2001.

[22] A. Pozio, M. De Francesco, A. Cemmi, F. Cardellini, L. Giorgi, Comparison of high surface Pt/C catalysts by cyclic voltammetry, J. Power Sources 105 (2002) 13-19.

[23] D.M. Himmelblau, Process Analysis by Statistical Methods, Wiley, New York, 1970. 


\section{List of Tables}

Table 1. Parameters used for the ammonia electrolyzer simulation as a CSTR reactor. 


\section{List of Figures}

Figure 1. Ammonia electrolysis set up used for the RTD experiments. A constant level of fluid was kept in the upper chamber of the gas collection system to maintain the pressure constant inside the electrolysis system. Insert parallel plate electrolyzer parts and configuration. Dimension units are in $\mathrm{cm}$.

Figure 2. Sustained periodic cyclic voltammograms obtained at $10 \mathrm{mV} \mathrm{s}^{-1}$ with Pt deposited on FNG electrode in $0.1 \mathrm{M} \mathrm{KOH}$ (solid thin line) and $0.1 \mathrm{M} \mathrm{KOH}+0.01 \mathrm{M} \mathrm{NH}_{4} \mathrm{Cl}$ (solid thick line). Sustained cyclic voltammograms obtained at $10 \mathrm{mV} \mathrm{s}^{-1}$ after the addition of $150 \mu \mathrm{L}$ of Yellow 5 dye in the $0.1 \mathrm{M} \mathrm{KOH}$ (dashed thin line) and $0.1 \mathrm{M} \mathrm{KOH}+0.01 \mathrm{M} \mathrm{NH}_{4} \mathrm{Cl}$ (dashed thick line), are also presented, which shows no significant effects of the Yellow 5 dye in the current potential profiles for ammonia electrooxidation. $\mathrm{H}_{\text {UPD }}$ region is observed from -0.75 to $0.4 \mathrm{~V}$ vs. $\mathrm{Hg} / \mathrm{HgO}$ while $\mathrm{NH}_{3}$ electrooxidation can be observed in the ammonia containing solutions ca. $-0.1 \mathrm{~V}$ vs. $\mathrm{Hg} / \mathrm{HgO}$.

Figure 3. Polarization curves of $\mathrm{Pt}$ deposited on framed $\mathrm{Ni}$ gauze electrode in $0.1 \mathrm{M} \mathrm{KOH}+0.01$ $\mathrm{M} \mathrm{NH}_{4} \mathrm{Cl}$ using Pt foil (४), and expanded Ni (匹) as auxiliary electrodes. a) Working electrode potential controlled versus reference electrode $\mathrm{Hg} / \mathrm{HgO}$. b) Measured cell voltage. Same current density can be obtained with both auxiliary electrodes under the same polarization of the working electrode. However, the cell voltage required for the expanded Ni electrode is higher than the Pt foil. Error bars show the standard deviation of the averaged measurements during the last five minutes of the potential step. 
Figure 4. Performance curves for the scan hold potential experiments performed to the deposited Pt on framed $\mathrm{Ni}$ gauze electrode in $0.1 \mathrm{MKOH}+0.01 \mathrm{M} \mathrm{NH}_{4} \mathrm{Cl}$ using Expanded $\mathrm{Ni}$ as auxiliary electrode. Oxidative scan rate a) and reductive scan rate c) were performed at $10 \mathrm{~m} \mathrm{~V} \mathrm{~s}^{-1}$. Upper limit potentials $-0.2(\square \cdot \square)$, $-0.15(\square \cdot \square)$, and $-0.1 \mathrm{~V}$ vs. $\mathrm{Hg} / \mathrm{HgO}$ ( $\square \square$ ) were hold for one hour. Then current and measured cell voltage profiles are shown in b) and d), respectively. Insert in figure b) zoom in the current profiles. The most stable current was obtained at $-0.2 \mathrm{~V}$ vs. $\mathrm{Hg} / \mathrm{HgO}$.

Figure 5. Residence time distribution in the ammonia electrolysis system obtained at a flow rate of $3 \times 10^{-2} \mathrm{~mL} \mathrm{~s}^{-1}$ of $200 \mu \mathrm{L} \mathrm{L}^{-1}$ Yellow 5 dye $+0.1 \mathrm{M} \mathrm{KOH}+0.01 \mathrm{M} \mathrm{NH}_{4} \mathrm{Cl}$ solution and an applied potential of $-0.2 \mathrm{~V}$ vs. $\mathrm{Hg} / \mathrm{HgO}$ compared against the CSTR model ( $\square \cdot \square$ ), the PFR model ( $\square \cdot \bullet$ ), the laminar flow reactor model ( $\square \square$ ), and the PFR-CSTR model ( $\square \square \square$ )

Figure 6. Current profiles of the flow electrolyzer with a volumetric flow rate of $1.8 \mathrm{~mL} \mathrm{~min}^{-1}$ of $0.1 \mathrm{M} \mathrm{KOH}+0.01 \mathrm{M} \mathrm{NH}_{4} \mathrm{Cl}$ solution and a constant applied potential of $-0.2 \mathrm{~V}$ vs. $\mathrm{Hg} / \mathrm{HgO}$. The dotted line shows the experimental data, while the continuous solid line shows the results obtained with the simulation of the electrolyzer as a CSTR with a correlation coefficient $\mathrm{R}^{2}=0.98$. Insert shows the catalyst coverage profile of $\theta_{N}(\square \cdot \square), \theta_{\mathrm{NH}},(\square \cdot \square)$, and $\theta_{\mathrm{NH}_{2}}($ $\neg \square)$ predicted by the simulation.

Figure 7. Ammonia fractional conversion profiles for the flow cell ammonia electrolyzer. Error bars on the experimental measurements $(\mathbf{\Lambda})$ represent the standard deviation of two sample measurements. Solid continuous line show the results obtained by mean of the electrolyzer simulation as a CSTR reactor. 
Figure 8. Current profiles of the flow electrolyzer with a volumetric flow rate of $1.8 \mathrm{~mL} \mathrm{~min}^{-1}$ of $0.15 \mathrm{M} \mathrm{KOH}+0.07 \mathrm{M} \mathrm{NH}_{4} \mathrm{Cl}$ solution and a constant applied potential of $-0.2 \mathrm{~V}$ vs. $\mathrm{Hg} / \mathrm{HgO}$. The dotted line shows the experimental data, while the continuous solid line shows the results obtained with the simulation of the electrolyzer as a CSTR. Insert shows the catalyst coverage profile of $\theta_{N}(\square \cdot \square), \theta_{N H},(\square \cdot \square)$, and $\theta_{N_{2}}(\square \square)$ predicted by the simulation. 


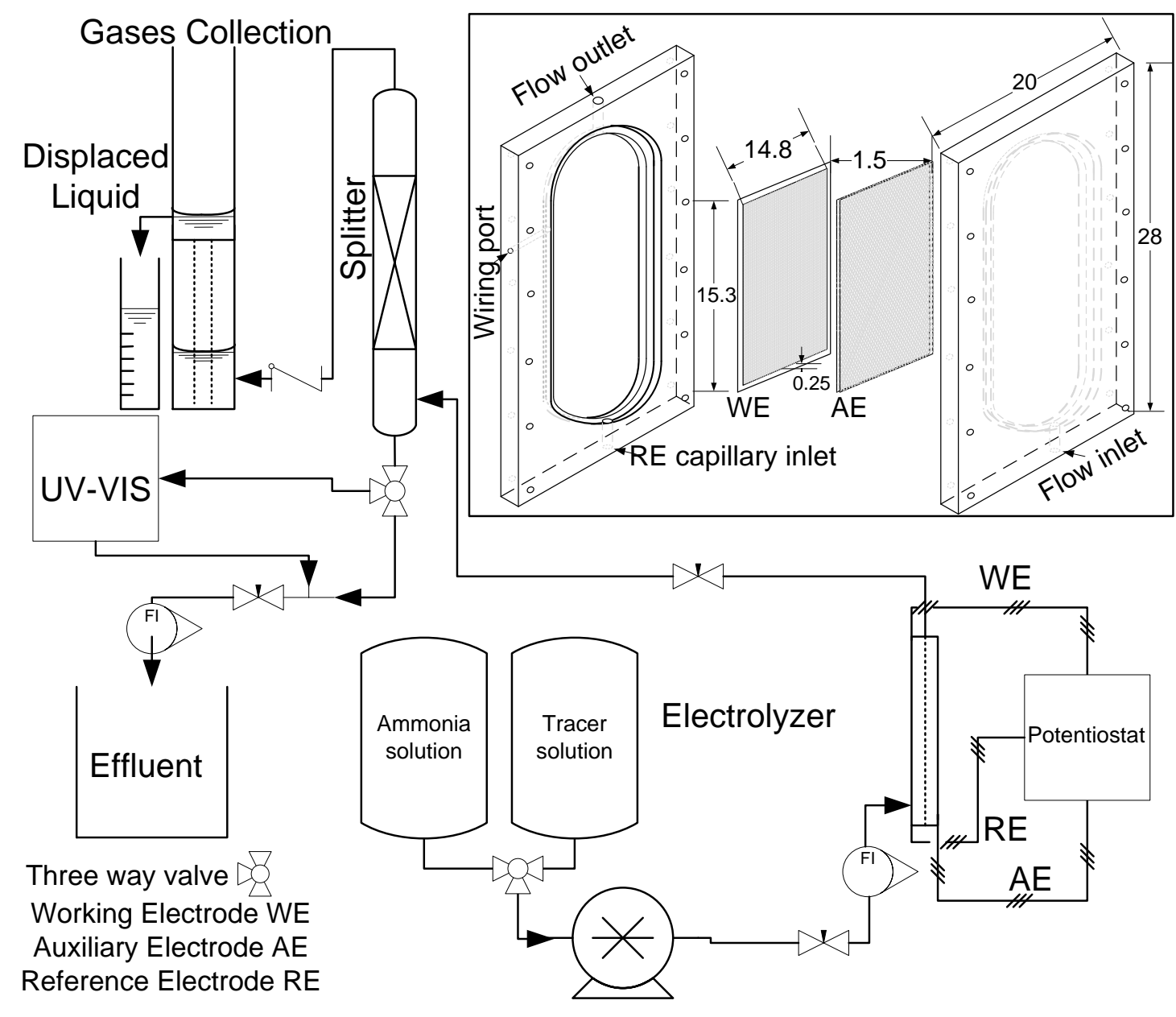

Figure 1. Diaz and Botte 


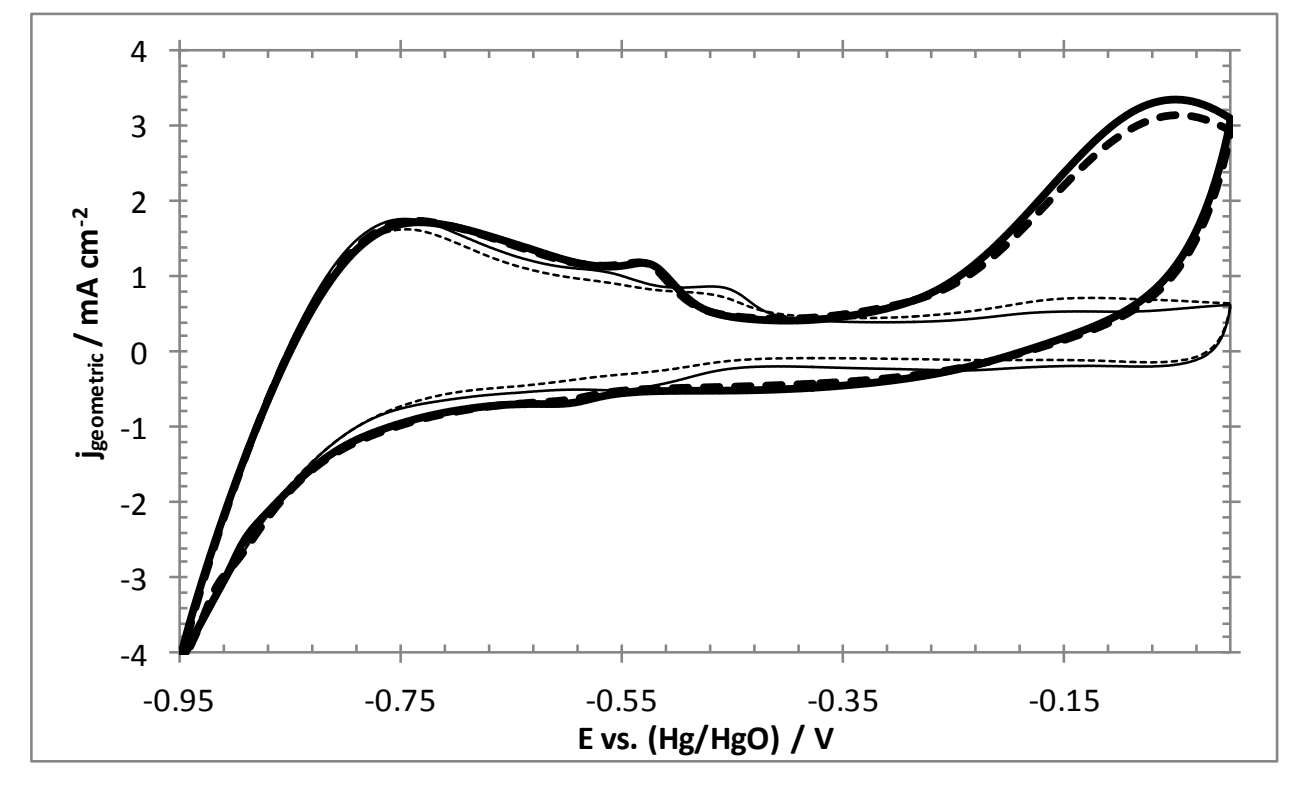

Figure 2. Diaz and Botte

Figure 2

Figure 2

Figure 2. Diaz and Botte

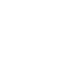



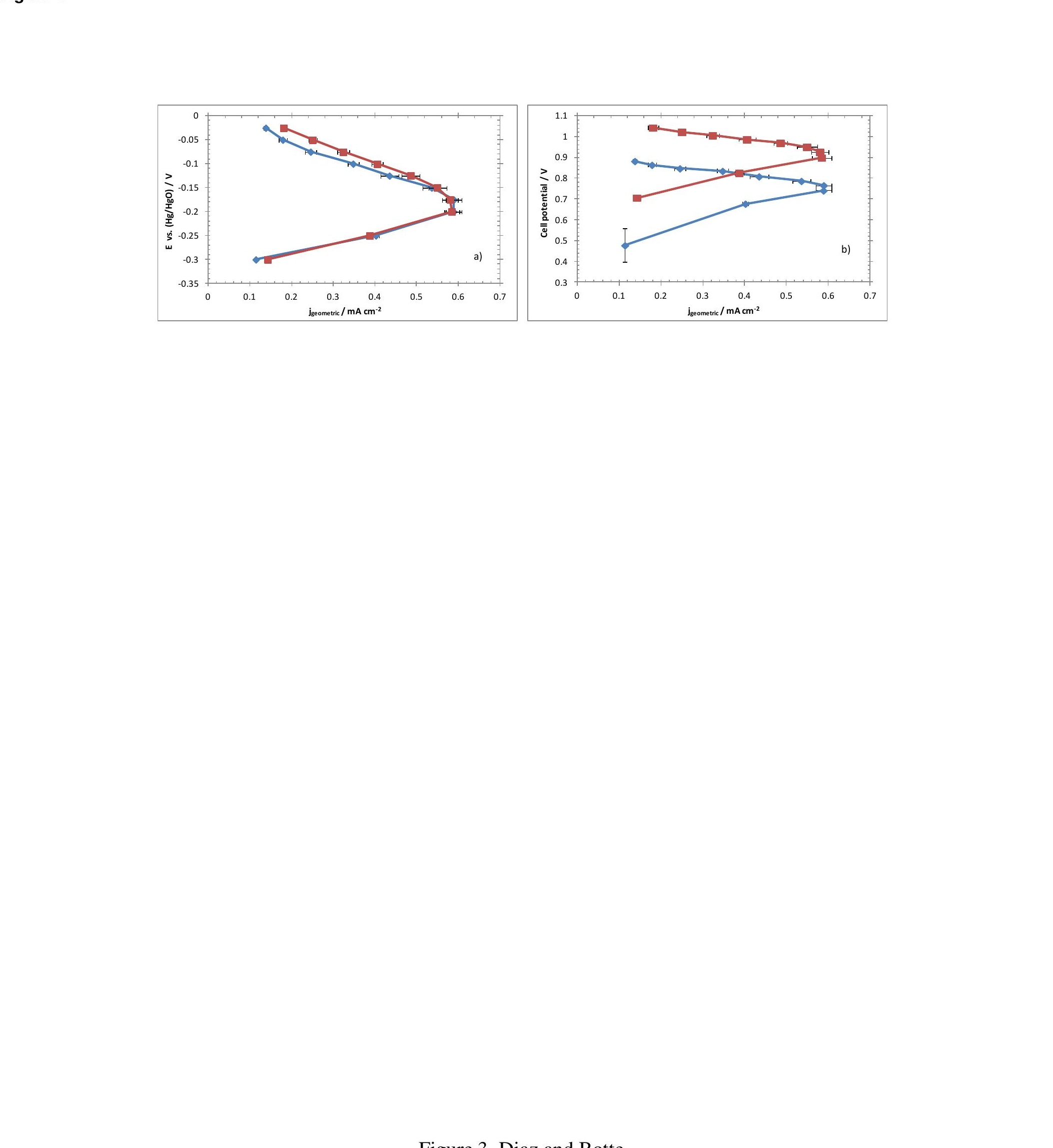

Figure 3. Diaz and Botte

Figure 3

3

.

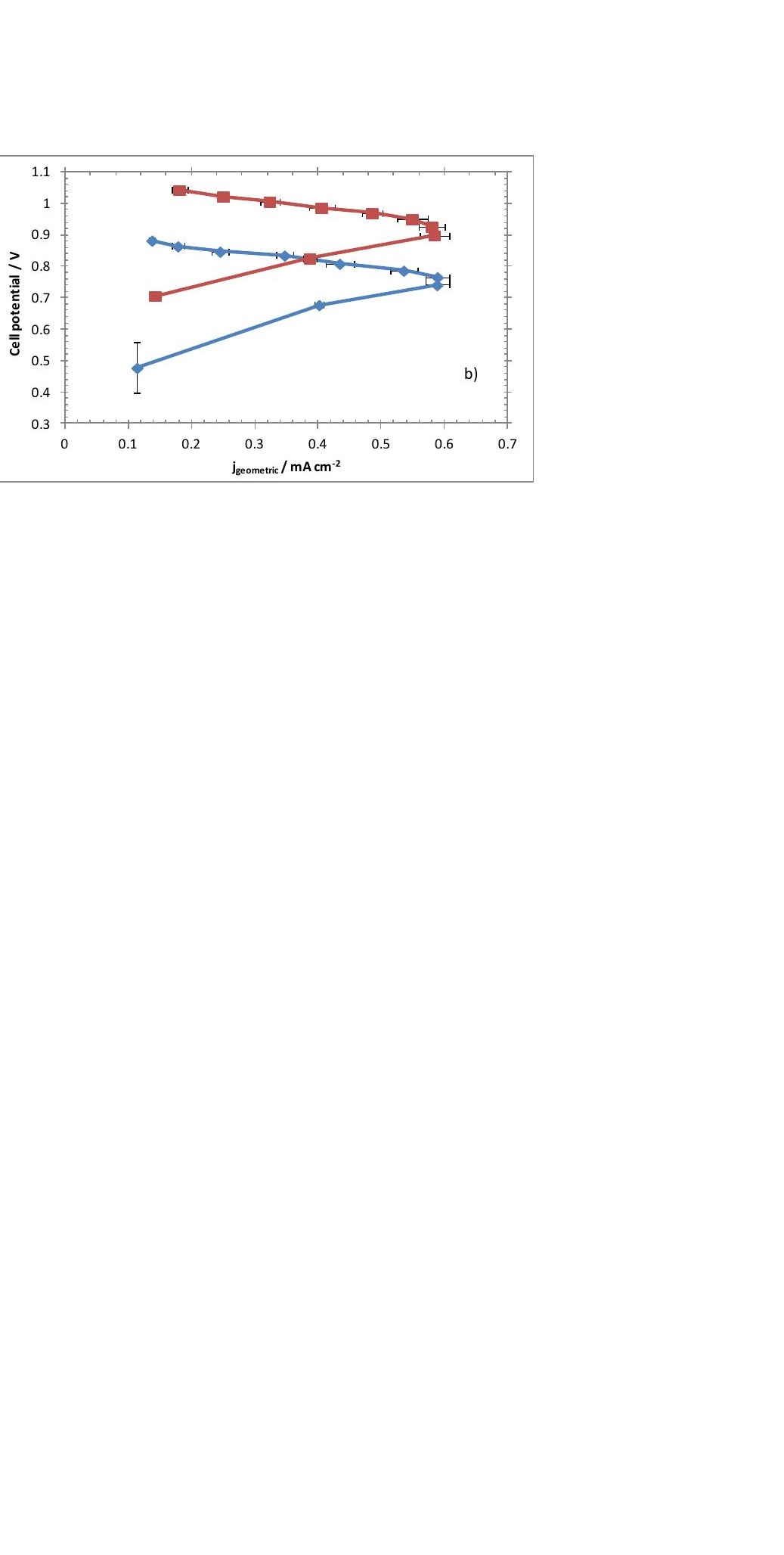

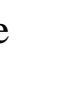

\section{Figure}

.

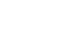

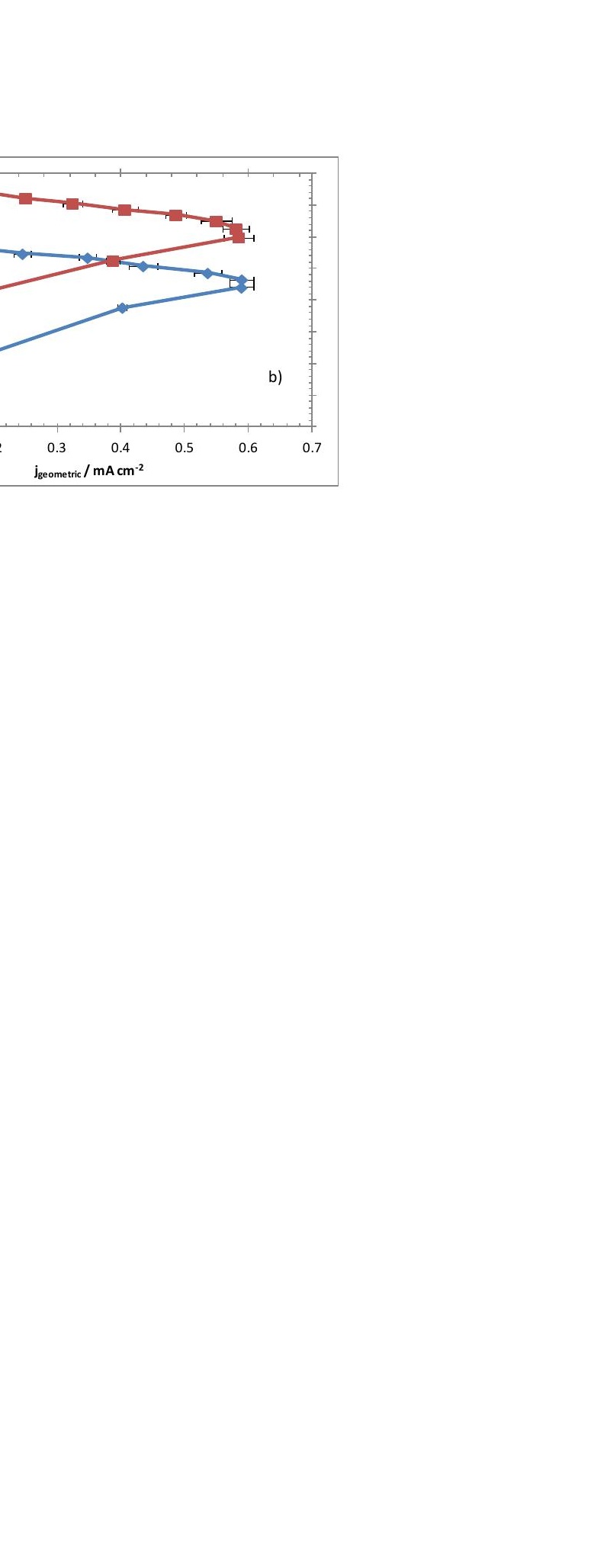

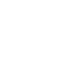

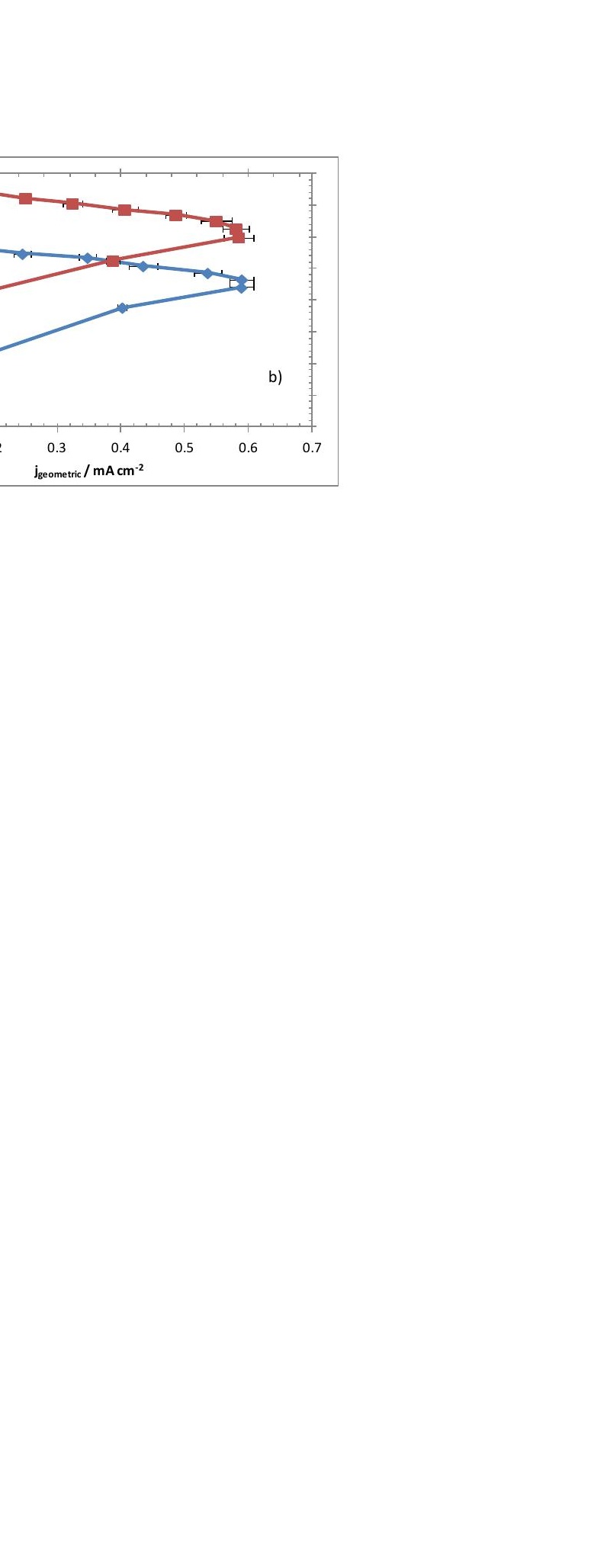

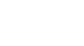

(2)

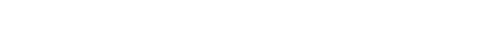


Figure 4
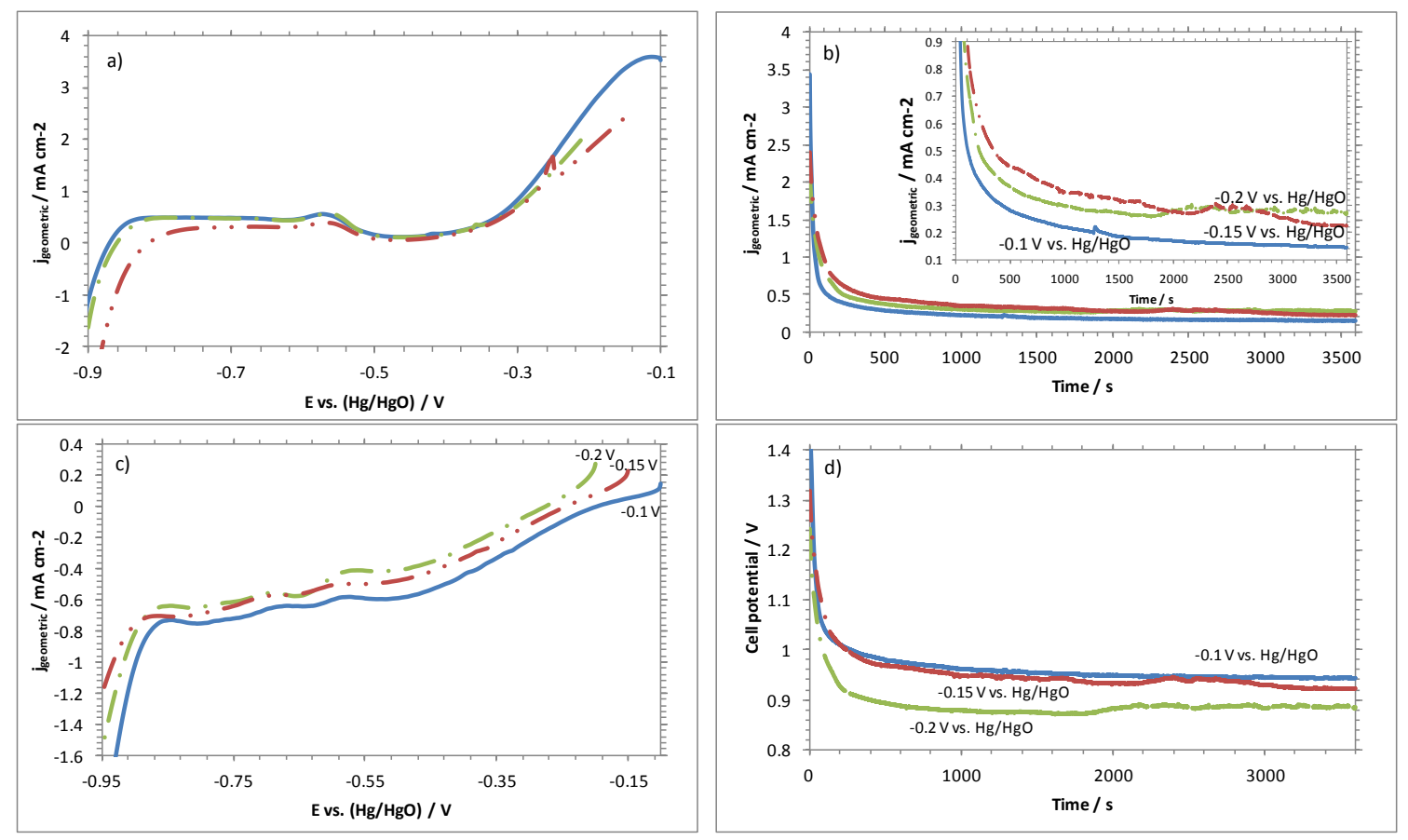

Figure 4. Diaz and Botte 


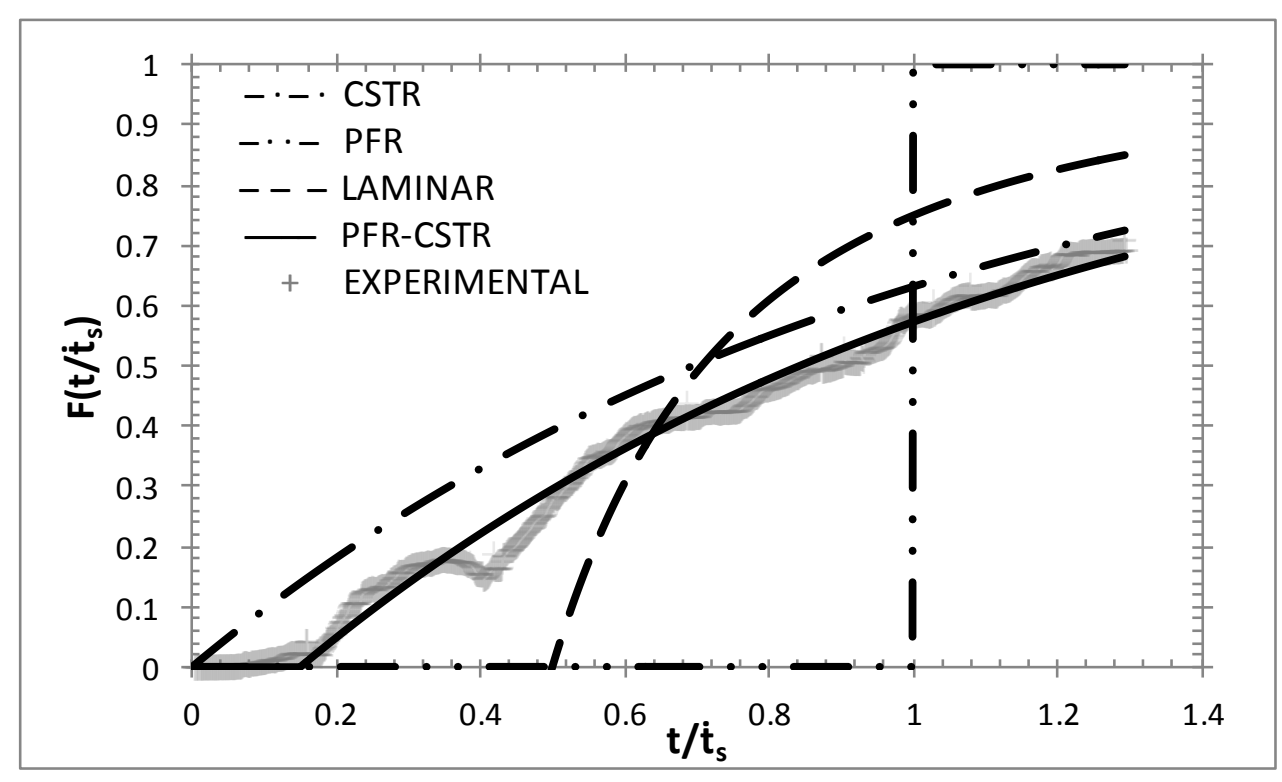

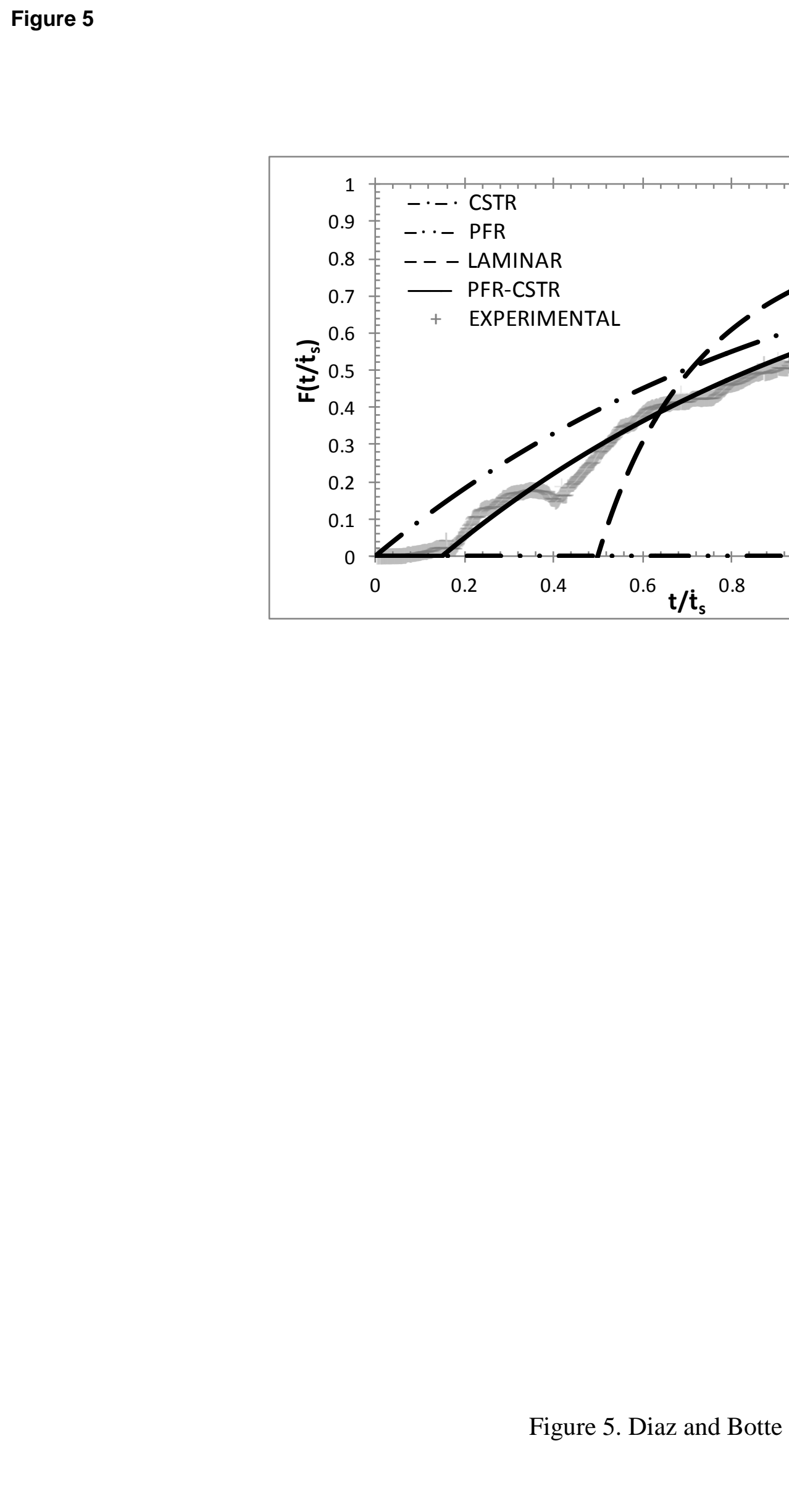

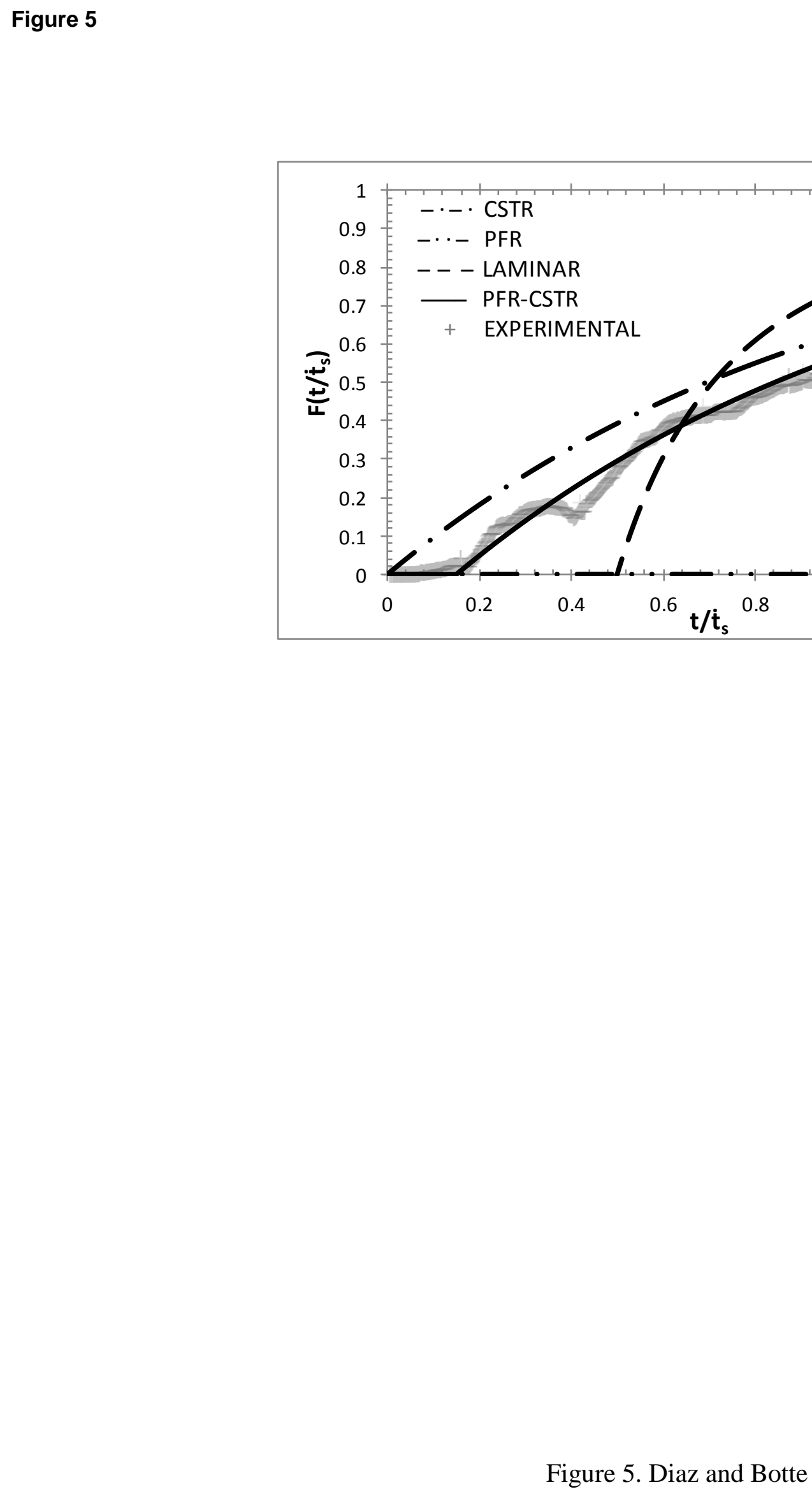

Figure 5. Diaz and Botte
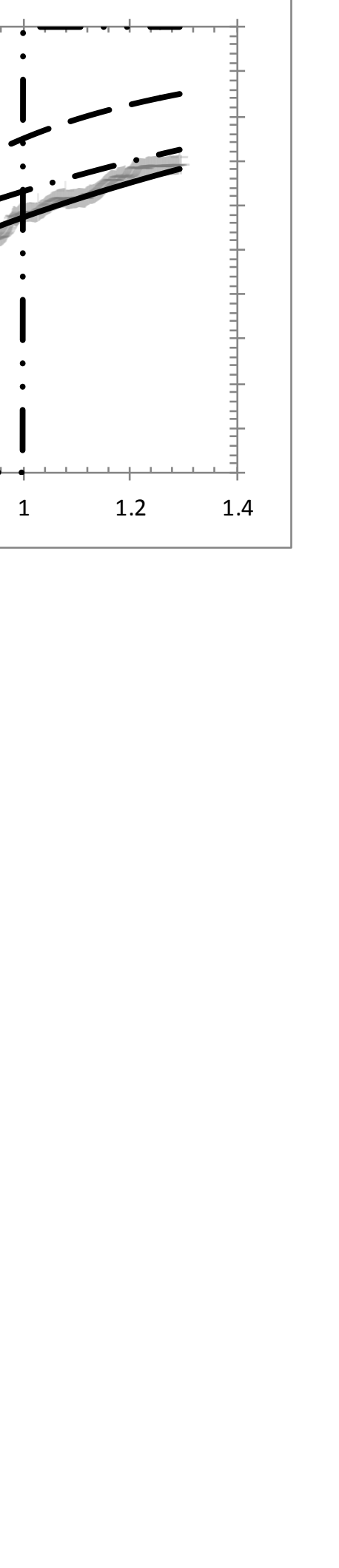
Figure 6

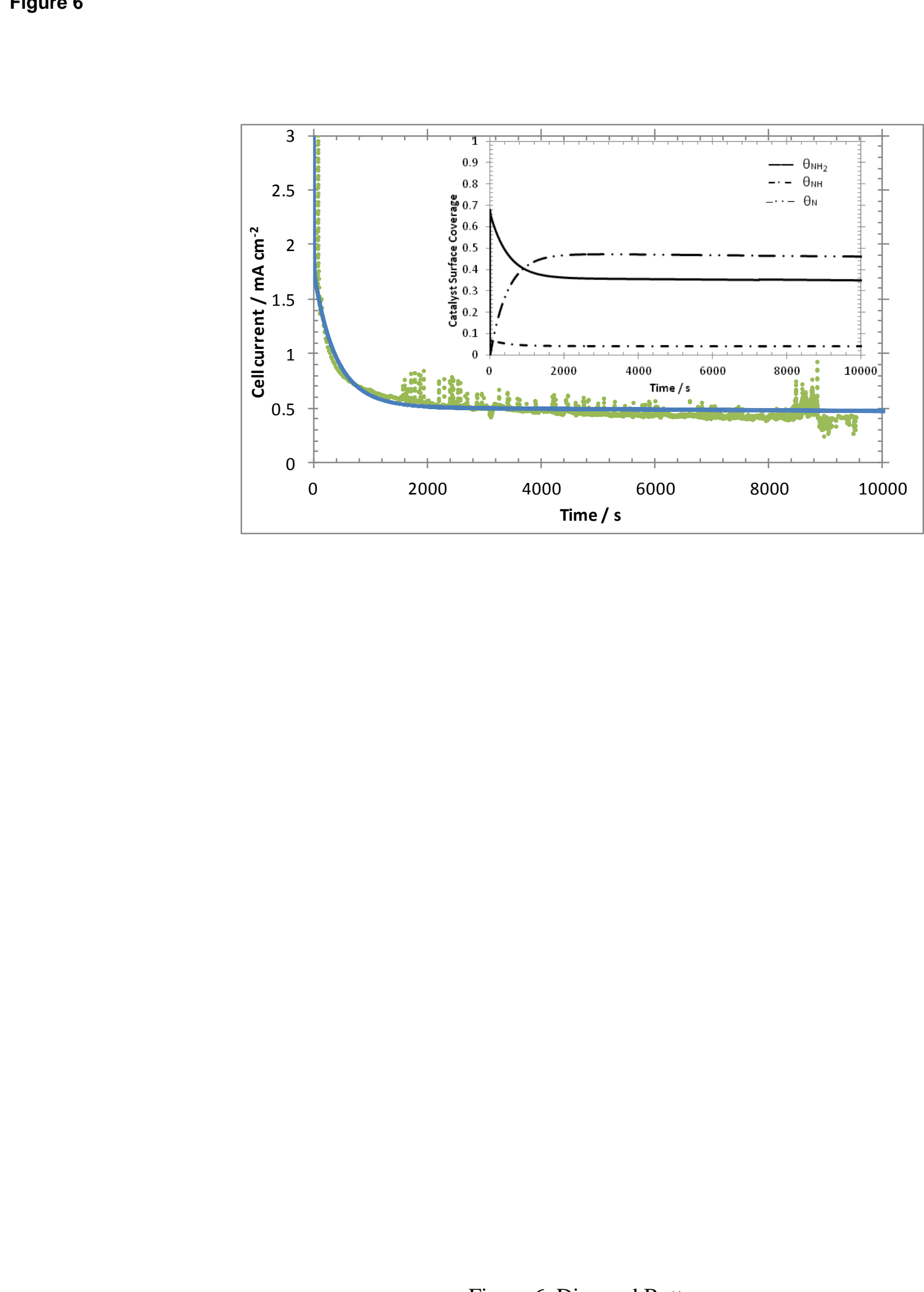

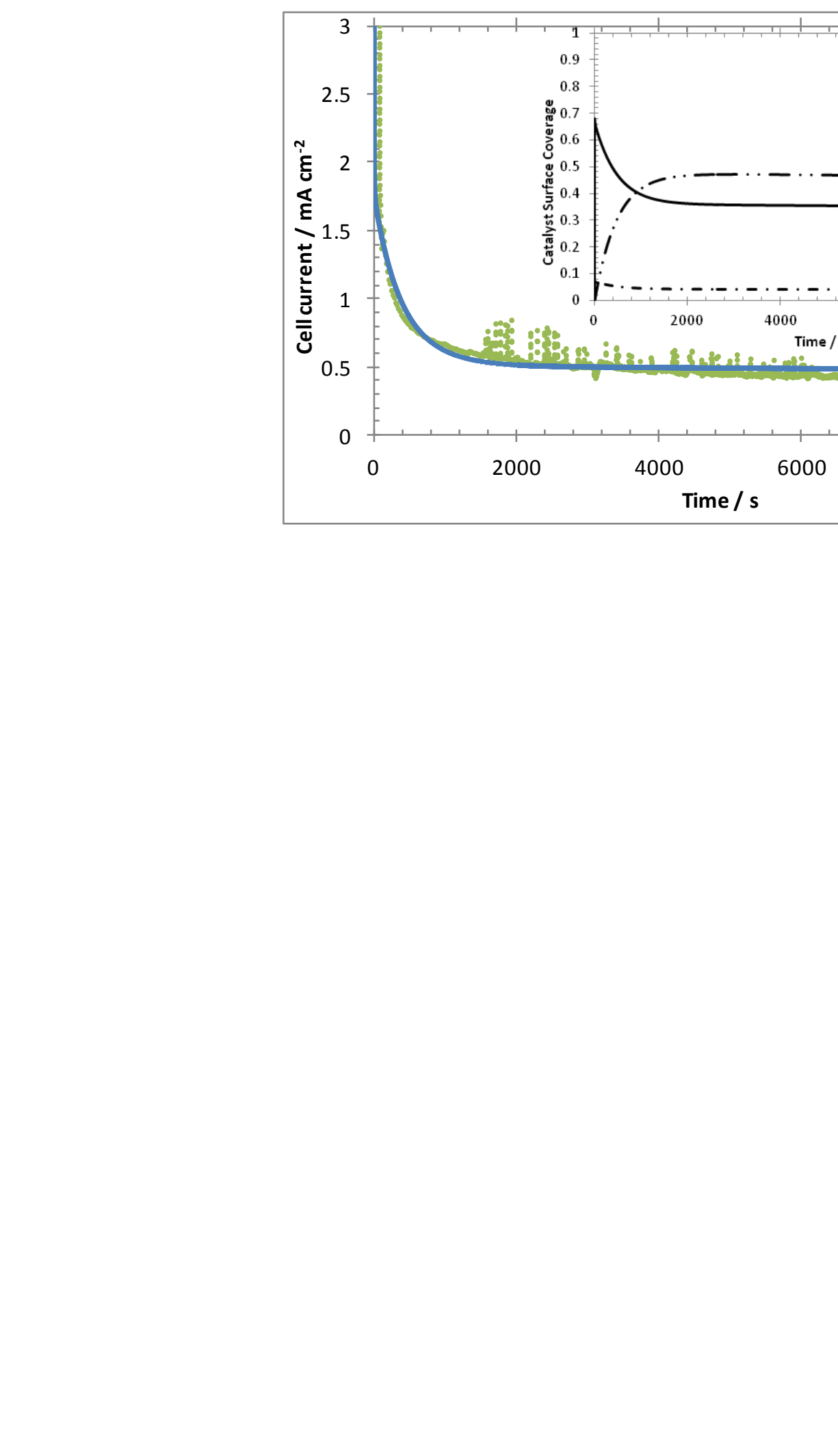

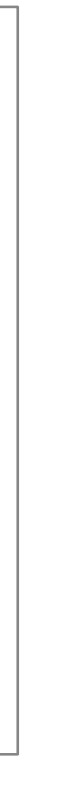

\footnotetext{
Figure 6. Diaz and Botte

(a)
}

(

,

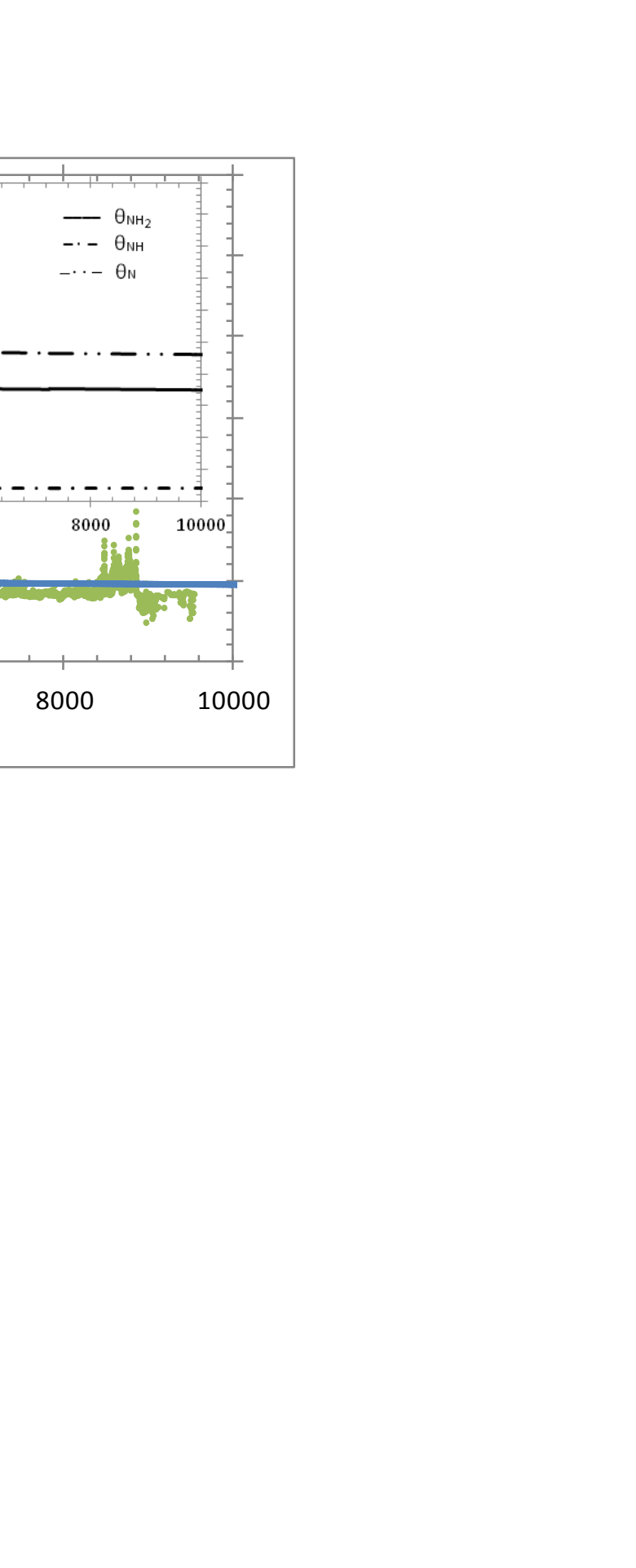

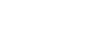




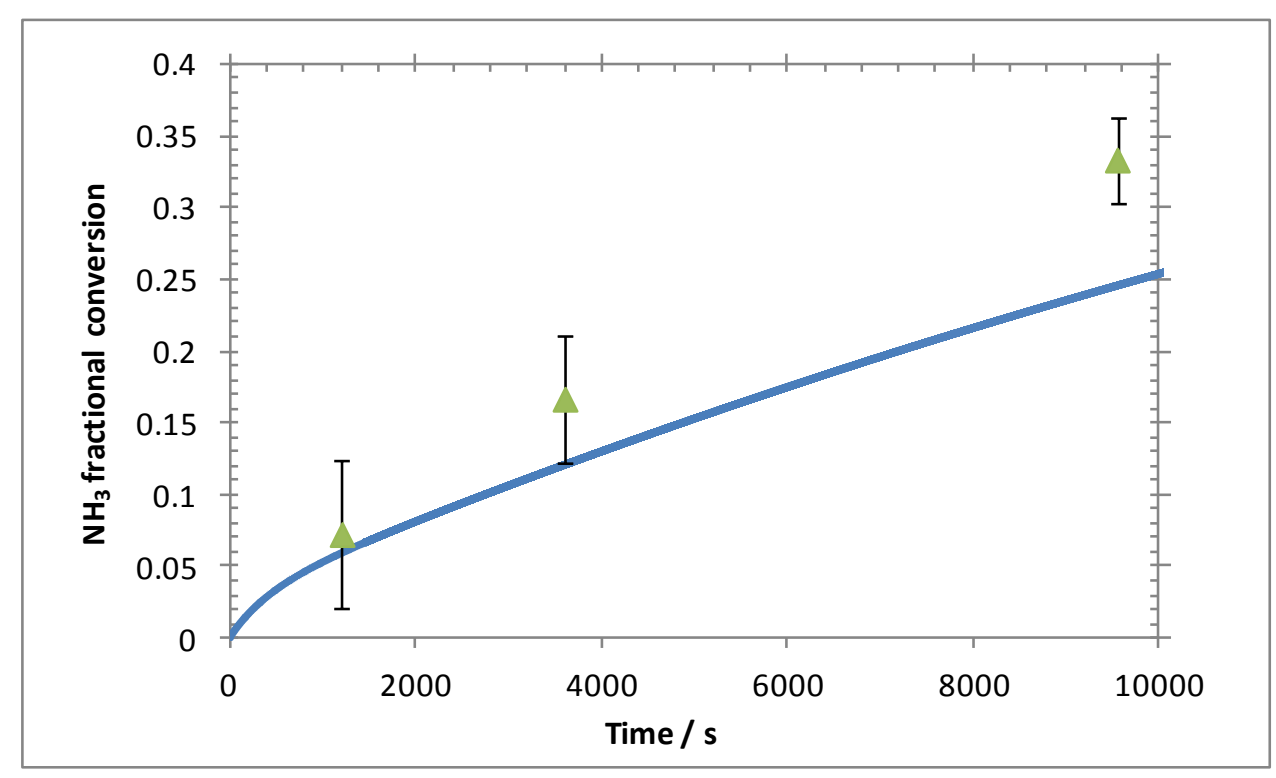

Figure 7. Diaz and Botte

Figure 7

\begin{abstract}
.
\end{abstract}

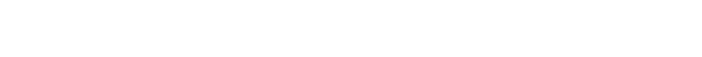

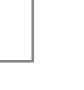


Figure 8

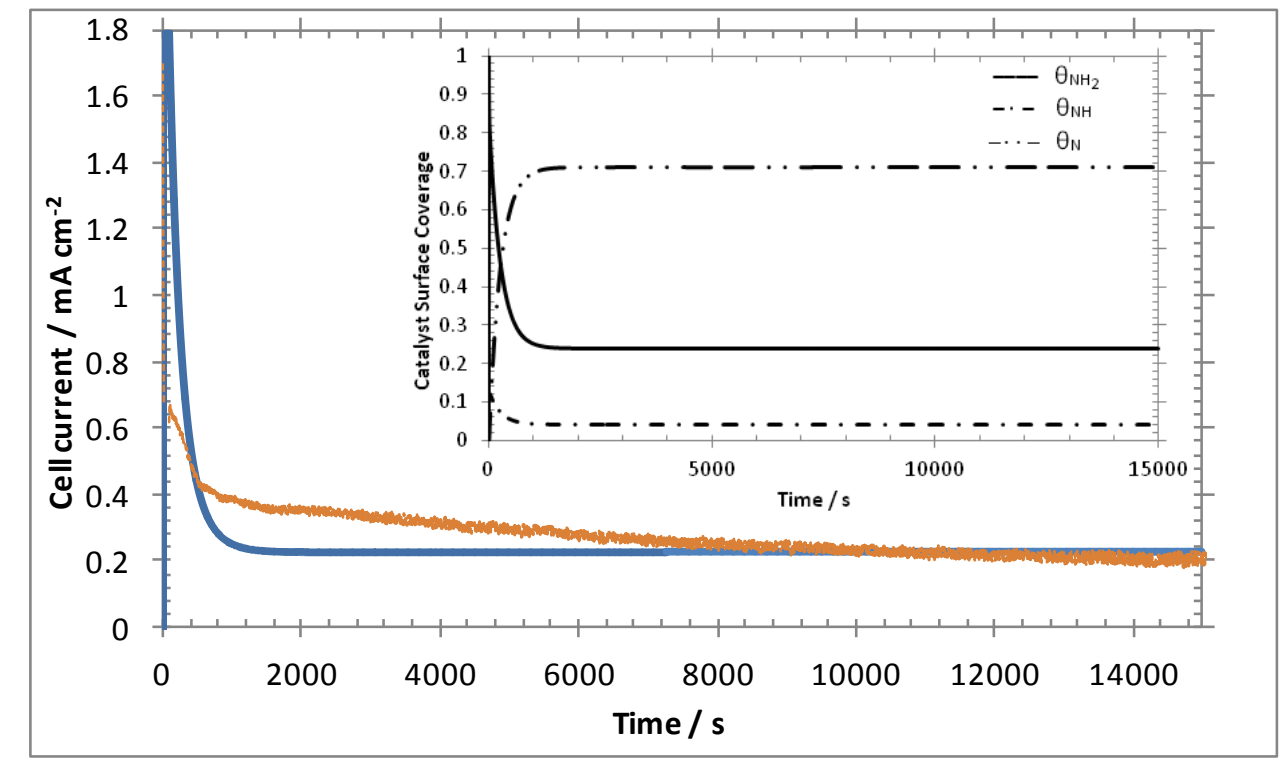

Figure 8. Diaz and Botte

Figure 8. Diaz and Botte

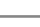

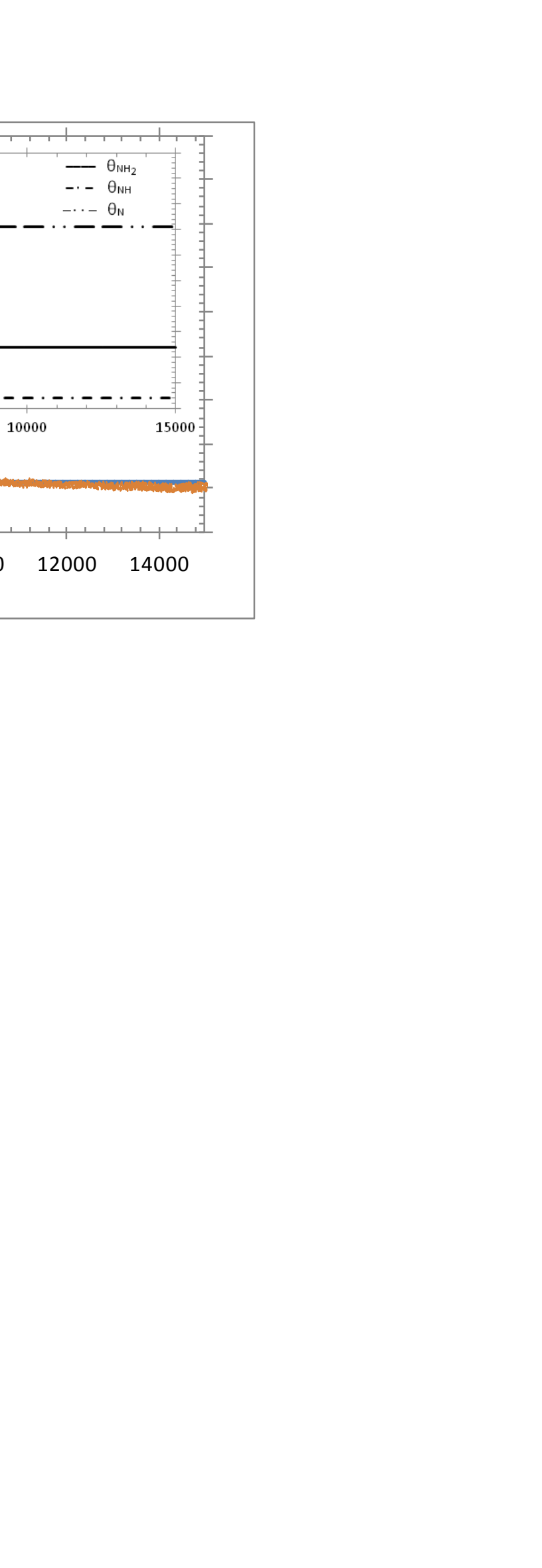

(1)
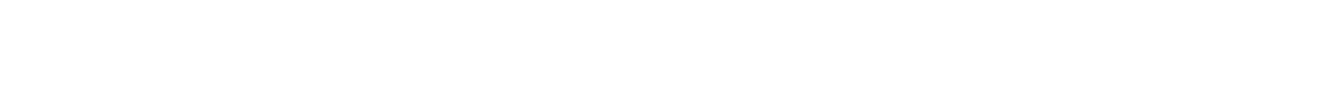
Table 1.

\begin{tabular}{|c|c|c|}
\hline SYMBOL & PARAMETER NAME & VALUE \\
\hline $\mathbf{T}$ & Temperature (K) & 298.15 \\
\hline $\mathbf{R}$ & Universal gas constant $\left(\mathrm{J} \mathrm{mol}^{-1} \mathrm{~K}^{-1}\right)$ & 8.314 \\
\hline $\mathbf{F}$ & Faraday constant $\left(\mathrm{C} \mathrm{mol}^{-1}\right)$ & 96482 \\
\hline Ujref $^{+}$ & Formal potential reaction 1, Eq. (5) (V vs. $\mathrm{Hg} / \mathrm{HgO})$ & -0.68 \\
\hline Ujref $_{4}^{+}$ & Formal potential reaction 4, Eq. (8) (V vs. $\mathrm{Hg} / \mathrm{HgO})$ & -0.21 \\
\hline Ujref $_{5}^{+}$ & Formal potential reaction 5, Eq. (9) (V vs. $\mathrm{Hg} / \mathrm{HgO})$ & -0.34 \\
\hline$k_{l f}^{+}$ & Forward reaction constant reaction 1, Eq. (5) $\left(\mathrm{cm}^{4} \mathrm{~s}^{-1} \mathrm{~mol}^{-1}\right)$ & $1.23 \times 10^{-4}$ \\
\hline$k_{1 b}$ & Backward reaction constant reaction 1, Eq. (5) $\left(\mathrm{mol} \mathrm{cm} \mathrm{c}^{-2} \mathrm{~s}^{-1}\right)$ & $3.73 \times 10^{-6}$ \\
\hline$k_{2 f}^{+}$ & Forward reaction constant reaction 2, Eq. (6) $\left(\mathrm{mol} \mathrm{cm}^{-2} \mathrm{~s}^{-1}\right)$ & $3.66 \times 10^{-10}$ \\
\hline $\boldsymbol{k}_{4 f}^{+}$ & Forward reaction constant reaction 4 , Eq. (8) $\left(\mathrm{cm} \mathrm{s}^{-1}\right)$ & $2.87 \times 10^{-7}$ \\
\hline $\boldsymbol{k}_{4 b}$ & Backward reaction constant reaction 4, Eq. (8) $\left(\mathrm{mol} \mathrm{cm} \mathrm{c}^{-2} \mathrm{~s}^{-1}\right)$ & $3.70 \times 10^{-10}$ \\
\hline$k_{5 f}^{+}$ & Forward reaction constant reaction 5, Eq. (9) $\left(\mathrm{cm} \mathrm{s}^{-1}\right)$ & $2.08 \times 10^{-8}$ \\
\hline$k_{5 b}$ & Backward reaction constant reaction 5, Eq. (9) $\left(\mathrm{mol} \mathrm{cm} \mathrm{cm}^{-2}\right)$ & $4.2 \times 10^{-11}$ \\
\hline$C_{\mathrm{NH}_{3} / t=0}$ & Initial value for ammonia concentration $\left(\mathrm{mol} \mathrm{cm}^{-3}\right)$ & $1.00 \times 10^{-5}$ \\
\hline$\left(\theta_{N H_{2}}, \theta_{N H}, \theta_{N}\right)_{/ \mathbf{t}=\mathbf{0}}$ & Initial concentration of adsorbed species (dimensionless) & 0 \\
\hline$\theta_{\mathrm{lt}=0}$ & Initial concentration of vacant active sites (dimensionless) & 1 \\
\hline $\mathbf{n}_{1}$ & number of electrons transferred reaction 1, Eq. (5) (dimensionless) & 1 \\
\hline $\mathbf{n}_{2}$ & number of electrons transferred reaction 3, Eq. (7) (dimensionless) & 4 \\
\hline $\mathbf{n}_{4}$ & number of electrons transferred reaction 4, Eq. (8) (dimensionless) & 1 \\
\hline $\mathbf{n}_{5}$ & number of electrons transferred reaction 5, Eq. (9) (dimensionless) & 1 \\
\hline$\Gamma$ & Surface concentration of active sites $\left.(\mathrm{mol} \mathrm{cm})^{-2}\right)$ & $2.18 \times 10^{-9}$ \\
\hline$\alpha_{1,4,5}^{+}$ & Transfer coefficient reaction 1,4 , and 5 & 0.5 \\
\hline$\Delta t$ & Time step size Euler method (s) & 0.24 \\
\hline
\end{tabular}

${ }^{+}$Kinetic parameters obtained from the mathematical modeling of ammonia electrooxidation in a rotating disk electrode [11]. 


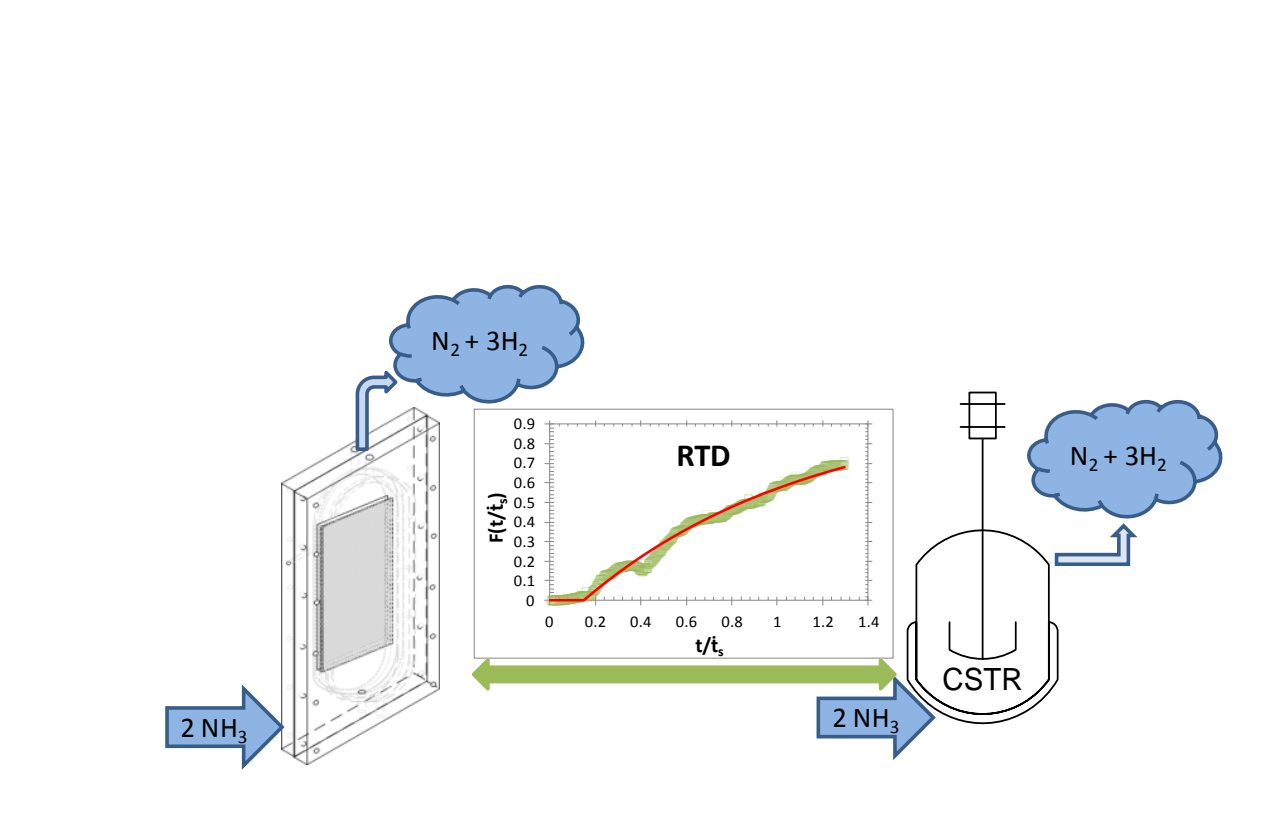

\section{Graphical Abstract (for review}

